\title{
Operational Strategy for Low-Carbon Supply Chain under Asymmetric Information of Fairness Concerns
}

\author{
Guangxing Wei $\mathbb{D},{ }^{1}$ Xu Zhang $\left(\mathbb{D},{ }^{1}\right.$ Xinghong Qin $\left(\mathbb{D},{ }^{2}\right.$ and Binta Bary $\mathbb{D}^{1}$ \\ ${ }^{1}$ School of Economics and Management, Chongqing Jiaotong University, Chongqing 400074, China \\ ${ }^{2}$ School of Management Science and Engineering, Chongqing Technology and Business University, Chongqing 400067, China \\ Correspondence should be addressed to Guangxing Wei; wgx777@126.com
}

Received 1 November 2021; Revised 5 January 2022; Accepted 7 January 2022; Published 10 February 2022

Academic Editor: Sundarapandian Vaidyanathan

Copyright (C) 2022 Guangxing Wei et al. This is an open access article distributed under the Creative Commons Attribution License, which permits unrestricted use, distribution, and reproduction in any medium, provided the original work is properly cited.

\begin{abstract}
Carbon emission reduction has become a common hot topic around the world. Although the previous literature has proven that the asymmetric information and fairness concerns would influence the operational strategy for low-carbon supply chain, it hardly touched the asymmetric information of fairness concerns, which contradicted practical observations and experimental evidence. Incorporating the asymmetric information of fairness concerns, this paper investigates a low-carbon supply chain consisting of a manufacturer and a retailer with discrete types including selfish S-type and fairness-concerned F-type. The manufacturer can observe and thereby know the behavioral type of the retailer in the scenario of symmetric information, while it cannot in the scenario of asymmetric information. In the approach of game theory, the optimal carbon emission reducing strategy and pricing strategy in the symmetric scenario and asymmetric scenario are achieved successively. By comparing the above two scenarios, the impacts stemming from the asymmetric information of fairness concerns at the individual level and systematic level are analyzed, respectively. A case study is offered before concluding some implications for the supply chain management. The findings include the following: Firstly, the asymmetric information of fairness concerns enhances the carbon emission reduction significantly. Although the fairness concerns alone decrease the carbon emission reduction, the asymmetric information increases with the dominating power. Secondly, the asymmetric information of fairness concerns raises the wholesale price and retail price dramatically. Although the impact of either fairness concerns or asymmetric information randomly changes with the behavioral type and information structure, their interactive impacts are stable and change smoothly. Thirdly, the asymmetric information of fairness concerns promotes a fairer profit distribution, while either fairness concerns or asymmetric information alone hardly changes the overall profit of the low-carbon supply chain.
\end{abstract}

\section{Introduction}

Reducing carbon emissions, as one of the core goals set in United Nations 2030 Agenda for Sustainable Development, is important for the whole world to realize global sustainable development. The high-level thematic debate of the 76th session of the United Nations General Assembly October 2021 is about delivering climate action. Many countries emphasize the importance to reduce carbon emissions and thereby made a series of plans. The largest developed country, the United States, officially rejoined the Paris climate accord February 2021. The largest developing country, China, plans to achieve the carbon peak by 2030 and carbon neutralization by 2060, President Xi Jinping promised at the general debate of the 75th session of the United Nations General Assembly September 2020. In both the industrial and academical views, reducing carbon emission and operational strategy of low-carbon supply chain have become a common hot topic around the world.

Industrially, sufficient carbon emission reduction is advantageous for the low-carbon supply chain to obtain competitiveness, because consumers with environmental awareness like to buy low-carbon products even with a higher price. For example, General Motors, one of the largest carmakers, announced to reach carbon neutralization by 2040, while Great Wall Motor of China plans by 2045 and 
Volkswagen sets by 2050. The operational strategy of the low-carbon supply chain includes product pricing and carbon emission reduction by adopting sustainable technology. On the side of the product pricing strategy, a high price can get a bigger marginal profit but decrease market demand, while a low price can increase market demand but cut the marginal profit. On the side of the carbon emissionreducing strategy, high reduction can attract more consumers but require heavier sustainable investments, while low reduction only requires lighter sustainable investments but attracts fewer consumers. Therefore, the low-carbon supply chain should trade off the carbon emission-reducing and product pricing strategy reasonably, where the manufacturer will take fairness into account although he in fact does not know whether the retailer behaves in a fairnessminded or selfish way, and then, the retailer may utilize such asymmetric information strategically.

Academically, many attentions have been paid to explore the operational strategy of the low-carbon supply chain in extant literature, which covers a wide area, such as the strategies of coordinating sustainable supply chain with green effort scheme and coordinating the socially responsible supply chain with carbon emissions tax by HosseiniMotlagh et al. [1, 2], respectively, the strategies where the retailer misreported carbon information by Yang et al. [3] and where the designer did not know the carbon reduction efficiency of the manufacturer by Yang et al. [4]. It has been proven that the asymmetric information in supply chain is popular and will influence the operational decision. For example, the operational strategies where the incumbent retailer possesses private information about the market demand were attained by Yun et al. [5], where the seller did not know the buyer's production cost by Raj et al. [6], where the manufacturer did not know the intensity of consumers' low-carbon preference by Li and Lai [7]. However, although the asymmetric information of market demand, production cost, etc. has been explored widely, the symmetric information of fairness concerns has hardly been touched. It also has been proven that the fairness concerns are popular and will influence the operational decision of supply chain. For example, the manufacturer in the low-carbon supply chain by Han et al. [8] and that in the green closed-loop supply chain by Jian et al. [9], both the manufacturer and the retailer in the low-carbon supply chain by Zou et al. [10], cared about fairness heavily when pursuing individual profits. However, although how the fairness concerns affect the operational strategy of supply chain has been discussed widely, few touched the symmetric information of fairness concerns. The literature about fairness concerns hardly corrects the widely adopted assumption that all supply chain members know that the specific partners are fairnessminded. It contradicts the practical observations extremely, by which the manufacturer usually cannot observe whether the retailer behaves in a fairness-minded or selfish way, and thereby the retailer may utilize such asymmetry strategically. It also contradicts the experimental evidence seriously. Katok and Pavlov [11] and Choi and Messinger [12] show that only the asymmetric information of fairness concern can explain the recorded experimental behaviors rationally.
Therefore, aiming at the above contradictions, this paper will incorporate the symmetric information of fairness concerns to analyze the following questions:

(1) What is the optimal operational strategy of the lowcarbon supply chain when the information of fairness concerns is asymmetric privately known?

(2) How do the fairness concerns influence the operational strategy? What are the impacts in the scenarios of symmetric information and asymmetric information, respectively?

(3) How does the asymmetric information of fairness concerns influence the operational strategy? What are the impacts at the individual level and systematic level, respectively?

By exploring the optimal operational strategy of the lowcarbon supply chain under asymmetric information of fairness concerns and analyzing the related impacts stemming from the asymmetric information of fairness concerns at the individual level of independent decision and systematic level of entire performance respectively, this paper acquires the following original contributions.

Firstly, it achieves the optimal operational strategy for the low-carbon supply chain under asymmetric information of fairness concerns. Previous literature examined either asymmetric information of market demand, individual cost, etc., or symmetric information of fairness concerns, but hardly touched the asymmetric information of fairness concerns.

Secondly, it investigates the impacts of fairness concerns on the operational strategy in the scenarios of symmetric information and asymmetric information, respectively. Previous literature only examined the symmetric scenario but hardly touched how the fairness concerns influence the operational strategy in the scenario of asymmetric information.

Thirdly, it addresses the impacts stemming from the asymmetric information of fairness concerns. Previous literature has analyzed either the impact of asymmetric information or the impact of fairness concerns separately but hardly touched the interactive impact of asymmetric information and fairness concerns.

Finally, it describes the impacts not only at individual level, but also at systematic level. Previous literature mainly focused on the level of individual decision such as decisionmaking of the wholesale price and retail price but hardly touched the level of systematic performance with exception of overall supply chain profit.

The paper is organized as follows. Section 2 reviews the related literature. Section 3 formulates the framework, assumptions, and notations. Section 4 probes the optimal operational strategy and its impact stemming from fairness concerns in the benchmark symmetric scenario. Section 5 examines the novel asymmetric scenario. By comparing the symmetric and asymmetric scenarios, Section 6 addresses the impact resulting from the asymmetric information of fairness concerns. Section 7 offers a case study. Section 8 presents the conclusion. 


\section{Literature Review}

In the relevant area of supply chain operational strategy under asymmetric information of fairness concerns, two branches of literature motivate this paper, including that about the asymmetric information in the supply chain and that about the fairness concerns in the supply chain. This section will elaborate on previous literature and clarify the gap between this paper and previous literature.

2.1. Asymmetric Information in Supply Chain. In the branch of asymmetric information, because managers always want to use the private information strategically, a lot of literature has been exploring the asymmetric information in context of the supply chain. However, it mainly focused on the asymmetric information of market demand, that of individual cost, etc., while it hardly touched the asymmetric information of fairness concerns.

The asymmetric information of market demand usually assumes that the retailer knows market demand more because he is closer to customers. Firstly, in the configuration of a two-echelon supply chain, Zhou et al. [13] investigated the pricing decision in a dual-channel supply chain. Chernonog and Avinadav [14] explored the advertising decision in a perishable products supply chain. Zhang and Xiong [15] scheduled the production plan in a make-tostock supply chain. Gan et al. [16] designed the commitment-penalty contract in a drop-shipping supply chain. Lei et al. [17] and Chen et al. [18] considered the asymmetric information of demand disruption. Zhang and Zhang [19] probed whether the seller with stochastic learning cost and the retailer preferred to select consistent contract type in a two-period supply chain. Yang and Ma [20] designed the two-part tariff contract in a supply chain with two competing suppliers and a dominant retailer. Yun et al. [5] designed the franchise contract and two-part tariff contract in a supply chain consisting of a supplier, an incumbent retailer possessing private information about market demand, and an entrant retailer. Secondly, in the configuration of a three-echelon supply chain, in a logistics service supply chain including a supplier, a third-party logistics service provider, and a retailer, $\mathrm{Ma}$ et al. [21] designed the costrevenue sharing contract to coordinate a fresh agricultural products supply chain, where the freshness-keeping effort of the third-party logistics service provider decides both quantity and quality, and the retailer privately knows the information about the market demand. In a dual supply chain including a supplier, a retailer, and an offline showroom with private information about market demand, $\mathrm{Li}$ et al. [22] designed the cooperative advertising contract to analyze the ill effect of asymmetric information and the spillover effect of cooperative advertisement. In a three-echelon supply chain including multiple suppliers, a manufacturer, and a retailer, Zhu et al. [23] solved the optimal decision making when the information of both component quality and market demand was asymmetric.

The asymmetric information of individual cost usually assumes that the supplier, manufacturer, and retailer privately know their own cost. Experimental evidence has shown that the asymmetric information of individual cost surely influences the operational decision and supply chain performance significantly as discussed by Qin et al. [24]. Firstly, in the configuration of manufacturer-retailer, Cao et al. [25] probed a store-brand supply chain, in which the dominant retailer did not know the manufacturer's production cost of national brands. Cao et al. [26] researched a dual-channel supply chain, in which the retailer privately owned her packaging cost. Secondly, in the configuration of seller/vendor-buyer, under asymmetric information of buyer's production cost, Raj et al. [6] investigated the optimal level of greening and corporate social responsibility, $\mathrm{Li}$ et al. [17] designed the coordination mechanism, and Zhang and Luo [27] designed the optimal quantity discount contract of coordinating a perishable products supply chain. Thirdly, in the configuration of supplier-manufacturer, Zhang et al. [28] explored a supply chain with a dominant supplier without knowing the production cost of the manufacturer. Yang et al. [29] addressed the reservation pricing strategy of a fashion supply chain, in which the manufacturer owned private information about production cost. Finally, some explored bilateral asymmetric information. For example, the manufacturer privately knew the information of his production cost, and the retailer privately knew the information of market demand as discussed by Wang et al. [30] or her selling cost by Gu et al. [31]. Mobini et al. [32] investigated the case, and both the processing cost of the retailer and market demand were asymmetric information.

Especially, a few touched on the asymmetric information in the low-carbon supply chain. Li and Lai [7] designed the abatement contract of a low-carbon supply chain, in which the manufacturer did not know the intensity of consumers' low-carbon preference. Wang and $\mathrm{He}$ [3] explored the incentive strategy for a low-carbon supply chain, in which the product designer did not know whether the carbon reduction efficiency of the manufacturer was high or low. Yang et al. [4] investigated the misreporting behaviors of carbon information and found that the leader would not lie about his carbon information even in the position of information advantage, but the retailer would either in an advantageous or in a disadvantageous position.

The above discussion shows that the asymmetric information, such as that of market demand and individual cost, is an important topic in the field of supply chain management not only industrially, but also academically. However, extant literature has been focusing on the asymmetric information of marked demand, individual cost, etc., while it never touched the asymmetric information of fairness concerns. The fairness concerns were always taken as the symmetric publicly known information; that is, all supply chain members are assumed to know that the specific partners are fairness-minded. It is inconsistent with the practical observations, where the manufacturer usually cannot observe whether the retailer behaves in a fairnessminded or selfish way, and thereby the retailer may utilize such asymmetric information strategically. Furthermore, previous literature has always analyzed the impacts from the asymmetric information in the individual level such as the 
decision-making of the wholesale and retail price but only covered the overall profit of the supply chain in the systematic level. To fill the above gaps, this paper will incorporate the asymmetric information of fairness concerns to explore the operational strategy under asymmetric information of fairness concerns and examine the impact stemming from the asymmetric information of fairness concerns at individual and systematic levels, which, respectively, treats each member independently and the lowcarbon supply chain as an entire system.

2.2. Fairness Concerns in Supply Chain. In the branch of fairness concerns, because managers may behave in a fairminded way, a lot of literature has been exploring how fairness concerns significantly influence decision-making and profit distribution in the supply chain. Additionally, the experimental evidence from Katok and Pavlov [11], Ho et al. [33], Qin et al. [24], Choi and Messinger [12], and so on verified it. The relevant literature incorporating fairnessconcerned behavior can be classified into single and dual cases, which are reviewed as follows, respectively.

In the single case, one member of the supply chain behaves in a fairness-minded way, while all others behave in a selfish way. Firstly, the manufacturer in the low-carbon supply chain is supposed to care about fairness as discussed by Han et al. [8]. No matter with or without an advantageous power, it appears analogous in the green closed-loop supply chain discussed by Jian et al. [9], mobile phone supply chain by Wang et al. [34], e-commerce supply chain by Wang et al. $[35,36]$, agricultural product supply chain by Yan et al. [37], dual-channel supply chain by $\mathrm{Li}$ et al. [38], and so on. Secondly, the retailer such as that in the low-carbon supply chain discussed by Zhou et al. [39], closed-loop supply chain by Sarkar and Bhala [40], dual-channel supply chain by $\mathrm{Du}$ and Zhou [41], sustainable supply chain by Liu et al. [42], and ternary supply chain with competitors by Nie and Du [43] is supposed to be fairness-minded. Thirdly, the recycler in the closed-loop supply chain is also supposed to mind fairness by Zhang et al. [44]. The similar is made to the collector in the closed-loop supply chain by Li et al. [45], the functional logistics service provider in the logistics service supply chain by Liu et al. [46], and the distributor in the three-tier supply chain by Tao et al. [47] no matter with dominant or dominated power.

In the dual case, two members of the supply chain behave in a fairness-minded way, although others still behave in a selfish way. Firstly, both the manufacturer and retailer are supposed to pay attention to fairness simultaneously in the low-carbon supply chain as discussed by Zou et al. [10] and Li and Lai $[7,48]$. The similar occurred in the green supply chain by Yang et al. [49], apparel supply chain by Adhikari and Bisi [50], agricultural product supply chain by Yan et al. [51], and dual-channel supply chain by Zhen et al. [52] no matter whatever the bargaining structure by Jiang et al. [53] and Pan et al. [54]. Secondly, dual fairness is rendered to the general contractor and the subcontractor in the construction supply chain as discussed by Jiang et al. [55], the functional logistics service provider and logistics service integrator by
Du and Han [56], the manufacturer and the network platform of e-commerce supply chain by Wang et al. [35], and the supplier and the retailer with competitors by Li et al. [57]. Thirdly, some discuss the interaction of fairness concerns and other behavioral factors. For example, Zhang et al. [58] analyzed the interactive effect between fairness concerns and overconfidence, and Huang et al. [59] probed how fairness concerns interacted with risk aversion.

The above discussion shows that the fairness concerns are important in the supply chain from both industrial and academic views. However, previous literature always examined fairness concerns under symmetric information, which assumed that everyone in the supply chain knew that the specific partners were fairness-minded. It contradicts the practical observations greatly. In practice, the manufacturer cannot observe whether the retailer behaves in a fairness-minded or selfish way, and thereby the retailer may utilize such asymmetric strategically through imitation and camouflage. It also contradicts the experimental evidence seriously. For example, Katok and Pavlov [11] and Choi and Messinger [12] found that only the asymmetric information of fairness concern can explain the recorded experimental behaviors rationally. Moreover, previous literature always analyzed the impacts of the fairness concerns in individual level, such as decisionmaking of the wholesale price and retail price, but only covered the overall supply chain profit in systematic level. Aiming at the above gaps, this paper will incorporate the asymmetric information of fairness concerns and thereby assumes that the manufacturer does not know whether the retailer behaves in a fairness-minded or selfish way, which is consistent with practical and experimental evidence.

Combining the above two branches, the literature about asymmetric information always focused on the asymmetric privately known information of market demand, individual cost, etc., while it hardly considered the asymmetric information of fairness concerns, and the literature about fairness concerns always adopted the assumption that the behavioral type was symmetric publicly known, while it hardly took the private behavioral information into account. Both sides contradict the practical observations and experimental evidence seriously. Practically, it is in fact difficult or even impossible to obtain full information about the behavioral type of supply chain partners. Experimentally, Katok and Pavlov [11], Ho et al. [33], and Choi and Messinger [12] found that the asymmetric information about the retailer's fairness concern was the most powerful to explain the supplier's behavior rationally.

Consequently, in order to resolve the above contradictions and thereby fill the gaps, this paper incorporates the asymmetric information of fairness concerns, to achieve the optimal operational strategy for the low-carbon supply chain under asymmetric information of fairness concerns and investigate the impacts of fairness concerns on the operational strategy in the scenarios of symmetric information and asymmetric information respectively, where the impacts stemming from the asymmetric information of fairness concerns are analyzed not only at the individual level of independent decision, but also at the systematic level of entire performance. 


\section{Problem Formulation}

3.1. Framework. The low-carbon supply chain consists of a manufacturer and a retailer, denoted as he/him and she/her, respectively, herein. Via the retailer, the manufacturer produces and sells the low-carbon products to consumers with environmental awareness.

The manufacturer behaves in a selfish way. To pursue maximum profit, the manufacturer decides the optimal wholesale price for the retailer and the optimal degree of carbon emission reduction by applying sustainable technology.

The retailer may be selfish or fairness-minded, defined as S-type and F-type, respectively. The S-type retailer, who only cares about her own profit, decides the optimal retail price to maximize her profit. The F-type retailer, who cares about both her own profit and the unfair profit distribution within the low-carbon supply chain, decides the optimal retail price to maximize her utility, which increases with her profit but decreases with the manufacturer's profit.

In the scenario of symmetric information, the manufacturer can observe and thereby knows the behavioral type of the retailer. Then, the manufacturer depends the carbon emission-reducing strategy and wholesale pricing strategy on the behavioral type of the retailer to maximize profit.

In the scenario of asymmetric information, the manufacturer cannot observe and thereby cannot depend the strategy on the behavioral type of the retailer anymore. The manufacturer needs to set a uniform strategy irrespective of whether the retailer is S-type or F-type. The goal changes from maximizing profit to pursuing maximum expected average profit, determined by the probability of F-type. The probability parameter is a publicly known given constant according to the Harsanyi Doctrine as discussed by Spence [60] and applied by $\mathrm{Ni}$ et al. [61].

Previous literature has been focusing on the scenario of symmetric information and has gotten the optimal operational strategy for the S-type retailer in the branch of classical supply chain, and that for the F-type retailer in the branch of behavioral supply chain.

However, the previous literature paid little attention to the scenario of asymmetric information, which is more popular. Practically, the manufacturer cannot observe and thereby does not know the behavioral type of the retailer. Only the retailer knows what and how much she cares about and even may hide the information strategically. Experimentally, neither fairness concern nor asymmetric information can explain the experimental findings rationally. The asymmetric information of fairness concern is the most rational power to explain the empirical and experimental behaviors in the supply chain as shown in Katok and Pavlov [11] and Choi and Messinger [12].

Consequently, aiming at the above contradiction, the following will investigate the optimal operational strategy under asymmetric information of fairness concerns and further explore how the asymmetric information of fairness concerns influences the operational strategy of the lowcarbon supply chain.

\subsection{Assumptions}

3.2.1. Market Demand. Driven by consumer environmental awareness, the market demand decreases with unit price but increases with carbon emission reduction. Similar to Ghosh and Shah [62], Sinayi Rasti-Barzoki [63], Wang et al. [34], and so on, the demand function is specified as $d=a-b p+\theta e$, where consumers like products with lower price and higher carbon emission reduction. The constant $a$ denotes the potential maximum demand, the coefficient $b$ represents the price sensitivity, and the variable $p$ measures the market price. The coefficient $\theta$ represents the low-carbon sensitivity, while the variable $e$ measures the degree of carbon emission reduction, which denotes the reduced proportion of carbon emission per unit product by applying sustainable technology into the manufacturing process. To focus on the issue of low-carbon operation, the demand function is further simplified as $d=a-p+\theta e$, which is widely taken in literature such as Nie and $\mathrm{Du}$ [43].

3.2.2. Sustainable Investment. The manufacturer adopts sustainable investment to reduce carbon emissions. The sustainable investment increases market demand, because consumers like environmentally friendly products more, but adds the product cost and successively enhances the wholesale price to the retailer, the cost to consumers. The manufacturer has to burden the cost $1 / 2 k e^{2}$ when adopting sustainable investment. The marginal sustainable coefficient $k$ is sufficiently bigger than other parameters as assumed in Swami and Shah [64], Zhou et al. [39], Wang et al. [34], and so on. The degree of carbon emission reduction $e$, which also occurs in the demand function, represents the reduced proportion of carbon emission reduced by applying sustainable technology.

3.2.3. Operational Strategy of the Manufacturer. On one side, the manufacturer should decide the degree of carbon emission reduction carefully. A high degree can attract more consumers but requires heavy sustainable investments. The low degree requires light sustainable investments but attracts fewer consumers. On the other side, the manufacturer should decide the wholesale price carefully. A high price can achieve a bigger marginal profit but decrease market demand, while the low price can increase market demand but cut the marginal profit. Consequently, the manufacturer has to balance the strategy of carbon emission-reducing and wholesale pricing to maximize profit.

3.2.4. Discrete Type of the Retailer. The behavioural type of the retailer is discretely binary. The S-type retailer, who only cares about her own profit, decides the optimal retail price to maximize her profit. The F-type retailer, who cares about both her own profit and the unfair profit distribution within the low-carbon supply chain, decides the optimal retail price to maximize her utility, which increases with her profit but decreases with the manufacturer's profit. Fairness intensity $\lambda$ measures how much the F-type retailer concerns the unfair 
profit distribution as adopted by Liu et al. [42] and Li et al. [57]. According to Fehr and Schmidt [65] and Li et al. [66], and so on, $0 \leq \lambda<1$. When $\lambda=0$, the retailer is S-type, only concerns about own profit, and does not care about the unfair profit distribution. When $\lambda>0$, the retailer is F-type, concerns both own profit and the manufacturer's profit, and suffers disutility from unfair profit distribution. Discretely, $\lambda=0$ denotes the $\mathrm{S}$-type, and $0<\lambda<1$ denotes the F-type. The probability of F-type is $0<\beta<1$ and $1-\beta$ for S-type. According to Spence [60] and Ni et al. [61], and so on, the parameter $\beta$ is a publicly known given constant.

3.2.5. Utility of the F-Type Retailer. According to Du et al. [67], Zhang et al. [68], and so on, the F-type retailer decides the optimal retail price to maximize her utility, which is specified as $u_{r f}=\pi_{r f}-\lambda\left(\pi_{m f}-\pi_{r f}\right)$. Specifically, $\pi_{r f}$ denotes the profit of the F-type retailer, $\pi_{m f}$ represents the profit of the manufacturer cooperating with the F-type retailer, $\pi_{m f}-\pi_{r f}$ describes the unfair profit distribution, $\lambda$ measures the fairness intensity, and $\lambda\left(\pi_{m f}-\pi_{r f}\right)$ represents the disutility suffered from the unfair distribution. The utility of the F-type retailer increases with her profit but decreases with that of the manufacturer.

3.2.6. Scenario of Symmetric Information. The behavioural type of the retailer is a publicly known knowledge. The manufacturer can observe the behavioural type of the retailer and thereby knows whether the retailer in the downstream of the low-carbon supply chain is S-type or F-type. Then, the manufacturer depends his strategy on the behavioural type of the retailer by setting the different strategy of carbon emission reducing and wholesale pricing $\left(e_{s}, w_{s}\right)$ for the S-type retailer and $\left(e_{f}, w_{f}\right)$ for the F-type retailer to maximize his profit $\pi_{m s}$ and $\pi_{m f}$ respectively. Given the carbon emission reduction and wholesale price $\left(e_{s}, w_{s}\right)$, the S-type retailer decides the optimal retail price $p_{s}$ to maximize her profit $\pi_{r s}$. Given the carbon emission reduction and wholesale price $\left(e_{f}, w_{f}\right)$, the F-type retailer decides the optimal retail price $p_{f}$ to maximize her utility $u_{r f}$.

3.2.7. Scenario of Asymmetric Information. The behavioural type of the retailer is a privately known knowledge. The manufacturer cannot observe and does not know the behavioural type of the retailer. Then, the manufacturer cannot depend his strategy on the behavioural type of the retailer anymore and has to set a uniform strategy of carbon emission reducing and wholesale pricing $(\bar{e}, \bar{w})$ although the retailer in the downstream of the low-carbon supply chain actually behaves in different ways, S-type or F-type. The manufacturer decides the optimal uniform strategy of carbon emission-reducing and wholesale pricing $(\bar{e}, \bar{w})$ to pursue the maximum average profit $\bar{\pi}_{m A}$, which is the mathematical expectation of random profit $\bar{\pi}_{m f}$ with probability $\beta$ and $\bar{\pi}_{m s}$ with probability $1-\beta$. Given the carbon emission reduction and wholesale price $(\bar{e}, \bar{w})$, the S-type retailer decides the optimal retail price $\bar{p}_{s}$ to maximize her profit $\bar{\pi}_{r s}$, and the F-type retailer decides the optimal retail price $\bar{p}_{f}$ to maximize her utility $\bar{u}_{r f}$.

3.3. Notations. Notations are summarized and listed as follows, where * denotes the optimal results.

(1) Parameters

$d=a-p+\theta e$ : Function of market demand, where $a$ denotes the potential maximum demand, $p$ presents the market price, $\theta$ is the low-carbon sensitivity, and $e$ measures the degree of carbon emission reduction as discussed by Nie et al. [43], Sinayi and Rasti-Barzoki [63], and so on.

$0<\beta<1$ : Probability of F-type, a publicly known given constant no matter under symmetric or asymmetric information as discussed by Spence [60] and applied by $\mathrm{Ni}$ et al. [61].

$c$ : Unit production cost of the manufacturer, $0<c<a$.

$k$ : Marginal sustainable coefficient, sufficiently large compared with other parameters as adopted by Swami and Shah [64], Zhou et al., [39], Wang et al. [34] and so on.

$\pi_{m s}, \bar{\pi}_{m s}$ : Profit of the manufacturer cooperating with an S-type retailer under symmetric/asymmetric information.

$\pi_{m f}, \bar{\pi}_{m f}$ : Profit of the manufacturer cooperating with an F-type retailer under symmetric/asymmetric information.

$\pi_{r s}, \bar{\pi}_{r s}$ : Profit of the S-type retailer under symmetric information and that under asymmetric information.

$\pi_{r f}, \bar{\pi}_{r f}$ : Profit of the F-type retailer under symmetric information and that under asymmetric information.

$u_{r f}, \bar{u}_{r f}$ : Utility of the F-type retailer under symmetric information and that under asymmetric information, specified as $u_{r f}=\pi_{r f}-\lambda\left(\pi_{m f}-\pi_{r f}\right)$ and $\bar{u}_{r f}=\bar{\pi}_{r f}-\lambda\left(\bar{\pi}_{m f}-\bar{\pi}_{r f}\right)$ respectively as discussed by Du et al. [67] and Zhang et al. [68], where $0<\lambda<1$ denotes the fairness intensity, which means how much the unfair distribution is concerned.

$\pi_{m A}, \bar{\pi}_{m A}:$ Average profit of the manufacturer at the systematic level under symmetric/asymmetric information.

$\pi_{r A}, \bar{\pi}_{r A}$ : Average profit of the retailer at the systematic level under symmetric/asymmetric information.

$\pi_{t A}, \bar{\pi}_{t A}$ : Average profit of the supply chain at the systematic level under symmetric/asymmetric information.

(2) Decision Variables

$e_{s}, e_{f}$ : Carbon emission reduction, decided by the manufacturer observing an S-type/F-type retailer under symmetric information. 
$w_{s}, w_{f}$ : Wholesale price, decided by the manufacturer observing an S-type/F-type retailer under symmetric information.

$\bar{e}$ : Uniform carbon emission reduction, decided by the manufacturer who does not know the behavioural type of the retailer under asymmetric information.

$\bar{w}$ : Uniform wholesale price, decided by the manufacturer who does not know the behavioural type of the retailer under asymmetric information.

$p_{s}, \bar{p}_{s}$ : Retail price, decided by the S-type retailer under symmetric information and that under asymmetric information.

$p_{f}, \bar{p}_{f}$ : Retail price, decided by the F-type retailer under symmetric information and that under asymmetric information.

\section{Operational Strategies in Scenario of Symmetric Information}

4.1. Optimization Model. Under symmetric information, the manufacturer can observe and know accurately the behavioural type of the downstream retailer. Therefore, the manufacturer depends the carbon emission-reducing strategy and wholesale pricing strategy on the behavioural type.

Specify the timing as follows:

Stage 1: the retailer occurs randomly with probability $\beta$ of being F-type and $1-\beta$ of being S-type, which is the common knowledge of the retailer and the manufacturer.

Stage 2: both the manufacturer and the retailer discover the behavioural type of each retailer, which thereby is a publicly known knowledge.

Stage 3: the manufacturer, who observes and thereby knows the behavioural type of the retailer, sets different strategies of carbon emission reduction and wholesale price, $\left(e_{s}, w_{s}\right)$ for the S-type, and $\left(e_{f}, w_{f}\right)$ for F-type retailer, respectively, which are defined as the sorted mechanism discussed by Wei et al. (2019).

Stage 4: the S-type and F-type retailer decide their retail prices $p_{s}$ and $p_{f}$ independently to maximize profit and utility, respectively.

Stage 5: the operational strategies are executed, where the decision-making of carbon emission reduction and

the price is carried out in Stages 3 and 4, and the manufacturer and the retailer gain their profits, respectively.

The approach of reverse reduction is adopted to get the optimal operational strategy.

Firstly, observing the carbon emission reduction and wholesale price decision of the manufacturer, the retailer decides the optimal retail price. Given the carbon emission reduction and wholesale price $\left(e_{s}, w_{s}\right)$, the S-type retailer determines the optimal retail price to pursue maximum profit. The decision problem faced by the S-type retailer is specified as $\max \underset{p_{s}}{\pi_{r s}}=\left(p_{s}-w_{s}\right)\left(a-p_{s}+\theta e_{s}\right)$. Similarly, given the carbon emission reduction and wholesale price $\left(e_{f}, w_{f}\right)$, the F-type retailer determines the optimal retail price to pursue maximum utility. The decision problem faced by the F-type retailer is $\max u_{r f}=\pi_{r f}-\lambda\left(\pi_{m f}-\pi_{r f}\right)$, $p_{f}$

where $\pi_{r f}=\left(p_{f}-w_{f}\right)\left(a-p_{f}+\theta e_{f}\right)$ is the profit of the F-type retailer and $\pi_{m f}=\left(w_{f}-c\right)\left(a-p_{f}+\theta e_{f}\right)-1 / 2 k e_{f}^{2}$ is the profit of the manufacturer.

Secondly, predicting the reaction function of the S-type and F-type retailer, which is embedded in the optimal solutions of the decision problems faced by the retailer, the manufacturer decides the optimal carbon emission reduction and wholesale price for the S-type and F-type retailer, respectively, to pursue maximum profit. Subject to the optimal retailer reaction, the decision problem faced by the manufacturer observing an S-type retailer and that in case of observing an F-type retailerare

$$
\begin{gathered}
\max \pi_{m s}=\left(w_{s}-c\right)\left(a-p_{s}+\theta e_{s}\right)-1 / 2 k e_{s}^{2}, \text { Deleted } \\
\max \pi_{e_{s}, w_{s}}=\left(w_{f}-c\right)\left(a-p_{f}+\theta e_{f}\right)-\frac{1}{2} k e_{f}^{2} .
\end{gathered}
$$

Finally, the optimization model of operational strategies under symmetric information is

$$
\begin{gathered}
\max _{\substack{e_{s}, w_{s} \\
\pi_{m s}}}=\left(w_{s}-c\right)\left(a-p_{s}+\theta e_{s}\right)-\frac{1}{2} k e_{s}^{2}, \\
\text { s.t. } \max \pi_{r s}=\left(p_{s}-w_{s}\right)\left(a-p_{s}+\theta e_{s}\right) . \\
\text { And, } \max _{p_{s}} \pi_{m f}=\left(w_{f}-c\right)\left(a-p_{f}+\theta e_{f}\right)-1 / 2 k e_{f}^{2},
\end{gathered}
$$

$$
\text { s.t. } \max \underset{p_{f}}{u_{r f}}=\left(p_{f}-w_{f}\right)\left(a-p_{f}+\theta e_{f}\right)-\lambda\left[\left(w_{f}-c\right)\left(a-p_{f}+\theta e_{f}\right)-\frac{1}{2} k e_{f}^{2}-\left(p_{f}-w_{f}\right)\left(a-p_{f}+\theta e_{f}\right)\right]
$$

where $e_{s}$ and $e_{f}$ denote the carbon emission-reducing strategy of the manufacturer observing an S-type and an F-type retailer, $w_{s}$ and $w_{f}$ denote the wholesale pricing strategy for the S-type and F-type retailer, and $p_{s}$ and $p_{f}$ represent the retail pricing strategy of the S-type and F-type retailer respectively.
4.2. Pricing Strategy. Solving the above optimization model, summarize the pricing strategy for the low-carbon supply chain in the scenario of symmetric information as follows.

Proposition 1. In the low-carbon supply chain under symmetric information, the manufacturer sets, respectively, the 
optimal wholesale price $w_{s}^{*}=2 k(a+c)-\theta^{2} c / 4 k-\theta^{2}$ for the $S$-type retailer and $w_{f}^{*}=-c \lambda \theta^{2}+2 a k \lambda+6 c k \lambda-c \theta^{2}+2 a k+$ $2 c k / 4 k(2 \lambda+1)-\theta^{2}(1+\lambda)$ for F-type retailer; the S-type retailer sets the optimal retail price $p_{s}^{*}=(3 a+c) k-\theta^{2} c / 4 k-\theta^{2}$; meanwhile, the F-type retailer sets the optimal retail price $p_{f}^{*}=$ $(2 \lambda+1)(3 a+c) k-c \theta^{2}(1+\lambda) / 4 k(2 \lambda+1)-\theta^{2}(1+\lambda)$.

Under symmetric information, the manufacturer, who can observe and thereby can depend the wholesale price on the behavioural type of the retailer, decides the optimal wholesale price according to the behavioural preference of the retailer, and the retailer decides the optimal retail price according to her own behavioural type. From Proposition 1, it can be found that $w_{s}^{*}>w_{f}^{*}$ and $\partial\left(w_{s}^{*}-w_{f}^{*}\right) / \partial \lambda>0, p_{s}^{*}>p_{f}^{*}$ and $\partial\left(p_{s}^{*}-p_{f}^{*}\right)$ $/ \partial \lambda>0$, which means that the fairness concerns will decrease the wholesale price and retail price. The increments improve with the fairness intensity. The stronger the fairness intensity, the more the attention paid to the unfair distribution, and the lower the wholesale price and retail price.

4.3. Emission Reducing Strategy. Solving the above optimization model, summarize the degree of carbon emission reduction for the low-carbon supply chain in the scenario of symmetric information as follows.

Proposition 2. In the low-carbon supply chain under symmetric information, the manufacturer sets, respectively, the optimal emission reducing strategy $e_{s}^{*}=\theta(a-c) / 4 k-\theta^{2}$ for the S-type retailer, and $e_{f}^{*}=\theta(a-c)(1+\lambda) / 4 k(2 \lambda+1)-$ $\theta^{2}(1+\lambda)$ for the F-type retailer.

Under symmetric information, the manufacturer, who can observe and thereby can depend the degree of carbon emission reduction on the behavioural type of the retailer, decides the carbon emission-reducing strategy according to the behavioural preference of the retailer. From Proposition 2 , it can be found that $e_{s}^{*}>e_{f}^{*}$ and $\partial\left(e_{s}^{*}-e_{f}^{*}\right) / \partial \lambda>0$, which means that the fairness concerns are disadvantageous for the carbon emission reduction, whose increment improves with the fairness intensity. The stronger the fairness intensity, the more the attention paid to the unfair distribution, and the less the carbon emission reduction.

4.4. Profitability. Solving the above optimization model, summarize the profitability of the low-carbon supply chain in the scenario of symmetric information as follows.

Proposition 3. In the low-carbon supply chain under symmetric information, the manufacturer gains the optimal profit $\pi_{m f}^{*}=k(\lambda+1)(a-c)^{2} / 2 \lambda\left(8 k-\theta^{2}\right)+8 k-2 \theta^{2}$ when observing an F-type retailer, $\pi_{m s}^{*}=k(a-c)^{2} / 8 k-2 \theta^{2}$ in case of $S$-type retailer; the $S$-type retailer and the F-type retailer achieve the optimal profit $\pi_{r s}^{*}=k^{2}(a-c)^{2} /\left(4 k-\theta^{2}\right)^{2}$ and $\pi_{r f}^{*}=k^{2}(a-c)^{2}(4 \lambda+1)(2 \lambda+1) /\left(4 k-\theta^{2}+\lambda\left(8 k-\theta^{2}\right)\right)^{2}$ respectively.

Under symmetric information, the profit of the manufacturer depends on the retailer's behavioural type, while that of the retailer is up to her own behavioural type. From Proposition 3, it can be found that $\pi_{m f}^{*}<\pi_{m s}^{*}$ and $\pi_{r f}^{*}>\pi_{r s}^{*}$, which means that the fairness concerns will decrease the manufacturer's profit but increase the retailer's profit. The fairness concerns influence the profits of the manufacturer and the retailer in the opposite directions. Furthermore, it also can be found that $\partial\left(\pi_{m s}^{*}-\pi_{m f}^{*}\right) / \partial \lambda>0$ and $\partial\left(\pi_{r f}^{*}-\right.$ $\left.\pi_{r s}^{*}\right) / \partial \lambda>0$, which means that the impact of the fairness concerns always improves with the fairness intensity despite being in the opposite directions.

\section{Operational Strategies in Scenario of Asymmetric Information}

5.1. Optimization Model. Under asymmetric information, the manufacturer cannot observe and thereby does not know the behavioural type of the retailer. Even if he is in fact cooperating with an S-type retailer, the manufacturer supposes that the retailer is S-type with probability $1-\beta$ and F-type with probability $\beta$. Similarly, even if he is in fact cooperating with an F-type retailer, the manufacturer still supposes that the retailer is F-type with probability $\beta$ and S-type with probability $1-\beta$.

Illustrate the timing as follows:

Stage 1: the retailer occurs randomly with probability $\beta$ of being F-type and $1-\beta$ of being S-type, which is the common knowledge of the retailer and the manufacturer.

Stage 2: only the retailer discovers her own behavioural type, which is different from the symmetric scenario where not only the retailer but also the manufacturer knows the behavioural type of each retailer.

Stage 3: the manufacturer, who always supposes that the retailer is F-type with probability $\beta$ and S-type with probability $1-\beta$, sets a uniform strategy of carbon emission reduction and wholesale price $(\bar{e}, \bar{w})$ for both the S-type and F-type retailer, because he does not know the behavioural type of the retailer, which are defined as the pooled mechanism discussed by Wei et al. (2019). It differs from the symmetric scenario where the manufacturer sets different strategies $\left(e_{s}, w_{s}\right)$ for the S-type retailer and $\left(e_{f}, w_{f}\right)$ for the F-type retailer, respectively, because he knows the correct behavioural type of the retailer.

Stage 4: the S-type and F-type retailer decide their retail prices $\bar{p}_{s}$ and $\bar{p}_{f}$ independently to maximize profit and utility, respectively.

Stage 5: the operational strategies are executed, where the decision-making of carbon emission reduction and price is carried out in Stages 3 and 4, and the manufacturer and the retailer gain their profits, respectively.

The approach of reverse reduction is adopted to get the optimal operational strategy.

Firstly, given the uniform carbon emission reduction and wholesale price $(\bar{e}, \bar{w})$ offered by the manufacturer, the retailer decides the optimal retail price. To maximize the profit, the decision problem faced by the S-type retailer is $\max \bar{\pi}_{r s}=\left(\bar{p}_{s}-\bar{w}\right)\left(a-\bar{p}_{s}+\theta \bar{e}\right)$. To maximize the utility, that $\bar{p}_{s}$ faced by the F-type retailer is 
$\max \bar{u}_{r f}=\bar{\pi}_{r f}-\lambda\left(\bar{\pi}_{m f}-\bar{\pi}_{r f}\right)$, where $\bar{\pi}_{r f}=\left(\bar{p}_{f}-\bar{w}\right)(a-$ $\bar{p}_{f}$

$\left.\bar{p}_{f}+\theta \bar{e}\right)$ and $\bar{\pi}_{m f}=(\bar{w}-c)\left(a-\bar{p}_{f}+\theta \bar{e}\right)-1 / 2 k \bar{e}^{2}$ are, respectively, the profit of the F-type retailer and the profit of the manufacturer under asymmetric information.

Secondly, predicting the reaction function of the S-type and F-type retailer, respectively, which is embedded in the optimal solutions of the retailer's decision problems, the manufacturer decides the uniform carbon emission reduction and wholesale price for both S-type and F-type retailers to pursue the maximum average profit. Subject to the optimal retailer reaction, the decision problem faced by the manufacturer, who does not know whether the downstream is an F-type or S-type retailer, is max $\bar{\pi}_{m A}=\beta[(\bar{w}-c)(a-$ $\left.\left.\bar{p}_{f}+\theta \bar{e}\right)-1 / 2 k \bar{e}^{2}\right]+(1-\beta)\left[(\bar{w}-c)\left(a^{\bar{e}, \bar{w}} p_{s}+\theta \bar{e}\right)-1 / 2 k \bar{e}^{2}\right]$, where $\bar{e}$ and $\bar{w}$ denote the uniform carbon emission-reducing and wholesale pricing strategy under asymmetric information, and the publicly known given $\beta$ represents the probability of F-type.

Finally, the optimization model of operational strategy under asymmetric information is

$$
\begin{aligned}
& \max \bar{\pi}_{\bar{c}, \bar{w}}=\beta\left[(\bar{w}-c)\left(a-\bar{p}_{f}+\theta \bar{e}\right)-\frac{1}{2} k \bar{e}^{2}\right]+(1-\beta)\left[(\bar{w}-c)\left(a-\bar{p}_{s}+\theta \bar{e}\right)-\frac{1}{2} k \bar{e}^{2}\right], \\
& \text { s.t. }\left\{\begin{array}{l}
\max _{\bar{p}_{s s}}=\left(\bar{p}_{s}-\bar{w}\right)\left(a-\bar{p}_{s}+\theta \bar{e}\right) \\
\max \bar{u}_{r f}=\left(\bar{p}_{f}-\bar{w}\right)\left(a-\bar{p}_{f}+\theta \bar{e}\right)-\lambda\left[(\bar{w}-c)\left(a-\bar{p}_{f}+\theta \bar{e}\right)-\frac{1}{2} k \bar{e}^{2}-\left(\bar{p}_{f}-\bar{w}\right)\left(a-\bar{p}_{f}+\theta \bar{e}\right)\right]
\end{array},\right.
\end{aligned}
$$

where the uniform carbon emission reduction $\bar{e}$ and wholesale price $\bar{w}$ do not differentiate the behavioral type, because the manufacturer cannot observe the behavioural type of the retailer, while the retail prices $\bar{p}_{s}$ and $\bar{p}_{f}$ are still up to the behavioral type, because each retailer of course always knows its own type.

Comparing the symmetric and asymmetric scenarios, the manufacturer adopts the sorted mechanism in symmetric scenario by setting different $\left(e_{s}, w_{s}\right)$ and $\left(e_{f}, w_{f}\right)$ for S-type and F-type retailers respectively, because he can observe the behavioral types, while he implements the pooled mechanism in asymmetric scenario by setting the same $(\bar{e}, \bar{w})$ for different type retailers, because he cannot observe the behavioural types anymore. If the manufacturer takes the sorted mechanism in asymmetric scenario, he must consider the incentive compatibility constraints, which assure that the retailers do not pretend to choose the other. However, in the pooled mechanism, the same $(\bar{e}, t \bar{w})$ are set for retailers with different types. Because $(\bar{e}, t \bar{w})$ are the only choice, it is unnecessary to take the incentive compatibility constraints into account. The approach of pooled mechanism was also applied in Wei et al. [69] and so on.

5.2. Pricing Strategy. Solving the above optimization model, summarize the pricing strategy for the low-carbon supply chain in the scenario of asymmetric information as follows.

Proposition 4. In the low-carbon supply chain under asymmetric information, the manufacturer sets the same optimal uniform wholesale price for both the S-type retailer and F-type retailer $\bar{w}^{*}=c \lambda k\left(4 \beta^{2}+2\right)+2 a \lambda k+2 k(a+c)-$ $c \theta^{2}(1+\lambda) / 4 k+4 \lambda k\left(\beta^{2}+1\right)-\theta^{2}(1+\lambda)$; the S-type retailer sets the optimal retail price $\bar{p}_{s}^{*}=2 \lambda k \beta^{2}(a+c)+k((\lambda+1))$ $(3 a+c)-c \theta^{2}(1+\lambda) \quad / 4 k\left(\lambda \beta^{2}+\lambda+1\right)-\theta^{2}(1+\lambda) ;$ meanwhile, the F-type retailer sets the optimal retail price $\bar{p}_{f}^{*}=$ $\lambda k \beta[a(2 \beta+1)+c(2 \beta-1)]+k(1+\lambda)(3 a+c)-c \theta^{2}(1+\lambda) /$ $4 k\left(\lambda \beta^{2}+\lambda+1\right)-\theta^{2}(1+\lambda)$.

Under asymmetric information, the manufacturer, who cannot observe and thereby cannot depend the wholesale price on the behavioural type of the retailer, should decide an optimal uniform wholesale price according to the probability distribution of F-type and S-type, and the retailer decides the optimal retail price based on her own behavioural type still. From Proposition 1, the following can be found. Firstly, $\partial \bar{w}^{*} / \partial \lambda<0$, the fairness concerns will decrease the wholesale price, which is similar with that in the scenario of symmetric information. Secondly, $\bar{p}_{f}^{*}-\bar{p}_{s}^{*}>0$ and $\partial\left(\bar{p}_{f}^{*}-\bar{p}_{s}^{*}\right) / \partial \lambda>0$, and the fairness concern will raise the retail price, whose increment improves with fairness intensity, which is contrary to the scenario of symmetric information absolutely. It results from the cross effect that the behavioural preference of the F-type retailer influences the pricing strategy of the S-type retailer under asymmetric information but does not under symmetric information.

Integrating the scenarios of symmetric and asymmetric information, conclude the impact of fairness concerns on the pricing strategy as the following corollary.

Corollary 1. The fairness concerns always decrease the wholesale price of the low-carbon supply chain no matter under symmetric or asymmetric information. However, the fairness concerns cut the retail price of the low-carbon supply chain under symmetric information but raise under asymmetric information. Moreover, all increments increase with the fairness intensity.

5.3. Emission Reducing Strategy. Solving the above optimization model, summarize the optimal degree of carbon emission reduction for the low-carbon supply chain in the scenario of asymmetric information as follows. 
Proposition 5. In the low-carbon supply chain under asymmetric information, the manufacturer sets the same uniform emission reducing strategy for both the S-type retailer and F-type retailer $\bar{e}^{*}=\theta(1+\lambda)(a-c) / 4 k+4 \lambda k\left(\beta^{2}+1\right)$ $-\theta^{2}(1+\lambda)$.

Under asymmetric information, the manufacturer, who does not know and thereby cannot depend the degree of carbon emission reduction on the behavioural type of the retailer, should decide a uniform emission reducing strategy according to the probability distribution of the behavioural type. From Proposition 5, it can be found $\partial \bar{e}^{*} / \partial \lambda=$ $-4 \theta k \beta^{2}(a-c) /\left(4 \lambda k \beta^{2}-\lambda \theta^{2}+4 \lambda k+4 k-\theta^{2}\right)^{2}<0, \quad$ which means that the fairness concerns are disadvantageous for the carbon emission reduction. The stronger the fairness intensity, the less the carbon emission reduction carried out, which is similar with that in the scenario of symmetric information.

Integrating the scenarios of symmetric and asymmetric information, conclude the impact of fairness concerns on the carbon emission-reducing strategy as the following corollary.

Corollary 2. The fairness concerns always are disadvantageous for the carbon emission reduction of the low-carbon supply chain no matter under symmetric or asymmetric information. Moreover, the increment increases with the fairness intensity.

5.4. Profitability. Solving the above optimization, summarize the profitability of the low-carbon supply chain in the scenario of asymmetric information as follows.

Proposition 6. In the low-carbon supply chain under asymmetric information, the manufacturer always supposes that the retailer is S-type with probability $1-\beta$ and F-type with probability $\beta$ because he cannot observe and does not know the behavioural type of the retailer and gains the optimal profit $\bar{\pi}_{m s}^{*}=k(1+\lambda)(a-c)^{2} \quad\left(8 k \lambda \beta^{2}+4 k \lambda+4 k\right.$ $\left.-\lambda \theta^{2}-\theta^{2}\right) / 2\left[4 k\left(\lambda \beta^{2}+\lambda+1\right)-(\lambda+1) \theta^{2}\right]^{2}$ when he is actually cooperating with an S-type retailer, and $\bar{\pi}_{m f}^{*}=k(1+$ $\lambda)(a-c)^{2}\left(8 k \lambda \beta^{2}-4 k \lambda \beta+4 k \lambda+4 k-\lambda \theta^{2}-\theta^{2}\right) / 2\left[4 k\left(\lambda \beta^{2}\right.\right.$ $\left.+\lambda+1)-(\lambda+1) \theta^{2}\right]^{2}$ in the case of an F-type retailer. The $S$-type and F-type retailers achieve the profit, respectively, $\bar{\pi}_{r s}^{*}=k^{2}(a-c)^{2}\left(2 \lambda \beta^{2}+\lambda+1\right)^{2} /\left[4 k\left(\lambda \beta^{2}+\lambda+1\right)-(\lambda+1)\right.$ $\left.\theta^{2}\right]^{2}$ and $\bar{\pi}_{r f}^{*}=k^{2}(a-c)^{2}\left(2 \lambda \beta^{2}+\lambda \beta+\lambda+1\right)\left(2 \lambda \beta^{2}\right.$ $-\lambda \beta+\lambda+1) /\left[4 k\left(\lambda \beta^{2}+\lambda+1\right)-(\lambda+1) \theta^{2}\right]^{2}$.

Under asymmetric information, the manufacturer cannot observe the behavioural type of the cooperated retailer and always supposes that the retailer is S-type with probability $1-\beta$ and F-type with probability $\beta$. Therefore, the manufacturer makes decisions of pricing strategy and emission-reducing strategy according to the publicly known probability distribution of F-type and S-type. The manufacturer's profit is a random variable relying on the probability distribution of behavioural type, that is, $\bar{\pi}_{m f}^{*}$ with probability $\beta$ and $\bar{\pi}_{m s}^{*}$ with probability $1-\beta$, whose average value is $\bar{\pi}_{m A}^{*}=\beta \bar{\pi}_{m f}^{*}+(1-\beta) \bar{\pi}_{m s}^{*}=k(a-c)^{2}(1+\lambda) / 8 \lambda k\left(\beta^{2}\right.$ $+1)-2 \theta^{2}(1+\lambda)+8 k$. It can be found that $\bar{\pi}_{m f}^{*}<\bar{\pi}_{m s}^{*}$, $\partial\left(\bar{\pi}_{m s}^{*}-\bar{\pi}_{m f}^{*}\right) / \partial \lambda>0$ and $\partial \bar{\pi}_{m A}^{*} / \partial \lambda=-4 k^{2} \beta^{2}(a-c)^{2} /\left(4 \lambda k \beta^{2}\right.$ $\left.-\lambda \theta^{2}+4 \lambda k+4 k-\theta^{2}\right)^{2}<0$, by which the fairness concerns will decrease the manufacturer's profit, which is similar to that in the scenario of symmetric information; $\bar{\pi}_{r s}^{*}-\bar{\pi}_{r f}^{*}=$ $k^{2} \beta^{2} \lambda^{2}(a-c)^{2} /\left(4 \lambda k \beta^{2}-\lambda \theta^{2}+4 \lambda k+4 k-\theta^{2}\right)^{2}>0, \quad \partial\left(\bar{\pi}_{r s}^{*}\right.$ $\left.-\bar{\pi}_{r f}^{*}\right) / \partial \lambda=2 k^{2} \beta^{2} \lambda(a-c)^{2}\left(4 k-\theta^{2}\right) /\left(4 \lambda k \beta^{2}-\lambda \theta^{2}+4 \lambda k+\right.$ $\left.4 k-\theta^{2}\right)^{3}>0$, by which the fairness concerns will also definitely decrease the retailer's profit irrespective of the retailer's behavioural type, which differs from that in the scenario of symmetric information. The bigger the fairness intensity, the more the impact of the fairness concerns on the profitability of the low-carbon supply chain.

Integrating the scenarios of symmetric and asymmetric information, conclude the impact of fairness concerns on the profitability of the low-carbon strategy as the following corollary.

Corollary 3. The fairness concerns decrease the manufacturer's profit no matter under symmetric or asymmetric information. However, the fairness concerns increase the retailer's profit under symmetric information but decrease the retailer's profit under asymmetric information whatever the behavioural type is. Moreover, the impact of fairness concerns on the profitability always increases with the fairness intensity.

Consistent with the case of the retail pricing decision, the impact of fairness concerns on the retailer's profit depends on whether the related information is symmetric or asymmetric. Under symmetric information, the fairness concerns cut the retail price and decrease the retailer's profit; under asymmetric information, the fairness concerns raise the retail price and increase the retailer's profit. It results from the cross effect also, by which the behavioural preference of the F-type retailer influences the pricing strategy and profit of the S-type retailer under asymmetric information although the S-type retailer behaves selfishly and does not pay any attention to fairness.

\section{Impacts of Asymmetric Information on Operational Strategies}

Comparing the above scenarios of symmetric and asymmetric information, explore the impacts stemming from the asymmetric information of fairness concerns on the pricing strategy, emission-reducing strategy, and profitability at two different levels. The individual level treats each member in the low-carbon supply chain independently and explores how the asymmetric information influences the individual decision and profit of each member. The systematic level treats the low-carbon supply chain as an entire system and investigates how the asymmetric information changes the operational performance of the supply chain.

\subsection{On Pricing Strategy}

6.1.1. Individual Level. The manufacturer decides the optimal wholesale price and the retailer decides the optimal retail price independently. Proposition 1 and Proposition 4 give the results of individual decisions under symmetric and asymmetric information respectively. By comparing them, 
illustrate the impact of asymmetric information on the pricing strategy at the level of individual decision as follows.

Theorem 1. $w_{f}^{*}<\bar{w}^{*}<w_{s}^{*} ; \partial\left(w_{s}^{*}-\bar{w}^{*}\right) / \partial \lambda>0, \partial\left(\bar{w}^{*}-w_{f}^{*}\right)$ $/ \partial \lambda>0 . \bar{p}_{s}^{*}<p_{s}^{*} ; \partial\left(p_{s}^{*}-\bar{p}_{s}^{*}\right) / \partial \lambda>0 . \bar{p}_{f}^{*}>p_{f}^{*} ; \partial\left(\bar{p}_{f}^{*}-p_{f}^{*}\right) / \partial \lambda$ $>0$.

Firstly, the manufacturer sets a single moderate wholesale price under asymmetric information, which is lower than that for the S-type retailer under symmetric information and higher than that for the F-type retailer under symmetric information. Moreover, not only the gap between the single moderate wholesale price under asymmetric information and that for the S-type retailer under symmetric information, but also the gap between the single moderate wholesale price under asymmetric information and that for the F-type retailer under symmetric information increases with the fairness intensity. In brief, the bigger the fairness intensity, the more the asymmetric information changing the individual decision of wholesale price.

Secondly, the S-type retailer sets a lower retailer price under asymmetric information than that under symmetric information. Moreover, the gap between the retail prices set by the S-type retailer under symmetric information and that under asymmetric information increases with the fairness intensity although the S-type retailer does not care about unfair distribution. The bigger the fairness intensity, the more the asymmetric information changing the S-type retailer's decision of retail price.

Thirdly, the F-type retailer sets a higher retailer price under asymmetric information than that under symmetric information. Moreover, the gap between the retail prices set by the F-type retailer under symmetric information and that under asymmetric information increases with the fairness intensity. The bigger the fairness intensity, the more the asymmetric information changing the F-type retailer's decision of retail price too.

Comparing the latter two cases, the impact of asymmetric information on the retail price is up to the concrete behavioural type of the retailer. The asymmetric information makes the S-type retailer cut down the retail price but makes the F-type retailer rise, although only the F-type retailer suffers disutility from unfair distribution.

Summarily, how the fairness concerns influence the individual decision of price depends on the condition of behavioural type and information structure and thereby changes randomly. The similar happens for the impact of asymmetric information.

6.1.2. Systematic Level. In the scenario of symmetric information, the manufacturer can observe the behavioural type of the retailer and thereby depend the wholesale price on the behavioural type of the retailer, denoted as $w_{f}^{*}$ and $w_{s}^{*}$ given in Proposition 1 , where the probability is $\beta$ and $1-\beta$ respectively. The average wholesale price of the low-carbon supply chain as an entire system under symmetric information is $w_{A}^{*}=\beta w_{f}^{*}+(1-\beta) w_{s}^{*}$. The retailer depends the retail price on her own behavioural type, respectively, denoted as $p_{f}^{*}$ and $p_{s}^{*}$ given in Proposition 1 , also with the probability $\beta$ and $1-\beta$. The average retail price of the low-carbon supply chain as an entire system under symmetric information is $p_{A}^{*}=\beta p_{f}^{*}+(1-\beta) p_{s}^{*}$.

In the scenario of asymmetric information, the manufacturer cannot observe the behavioural type of the retailer and thereby decides a uniform wholesale price $\bar{w}^{*}$ given in Proposition 4, which is independent on the behavioural preference of the retailer although the probability of F-type and S-type is still $\beta$ and $1-\beta$. The wholesale price of the lowcarbon supply chain as an entire system under asymmetric information is $\bar{w}_{A}^{*}=\bar{w}^{*}$, which is a certain value instead of expected value. However, even under asymmetric information, the retailer still depends the retail price on her own behavioural type, denoted as $\bar{p}_{f}^{*}$ and $\bar{p}_{s}^{*}$ given in Proposition 4 , respectively, and thereby the average retail price of the low-carbon supply chain as an entire system under asymmetric information is $\bar{p}_{A}^{*}=\beta \bar{p}_{f}^{*}+(1-\beta) \bar{p}_{s}^{*}$.

The difference between the above scenarios describes the impact of the asymmetric information on the pricing strategy at the level of systematically operational performance.

Theorem 2. $w_{A}^{*}<\bar{w}_{A}^{*} ; \partial\left(\bar{w}_{A}^{*}-w_{A}^{*}\right) / \partial \lambda>0$, with the exception illustrated by Domain $E$ in Figure 1. $p_{A}^{*}<\bar{p}_{A}^{*} ; \partial\left(\bar{p}_{A}^{*}\right.$ $\left.-p_{A}^{*}\right) / \partial \lambda>0$, with the exception of Domain $E$.

Systematically, the asymmetric information enhances the pricing strategy of the low-carbon supply chain, including the wholesale and retail prices. The stronger the fairness intensity, the more the attention paid to the unfair distribution, and the more the enhancements with a tiny exception. In the perspective of market, the asymmetric information decreases the competitiveness of the low-carbon supply chain, because the price rises. In the perspective of consumers, the asymmetric information decreases their welfares, because they have to pay more for the same low-carbon products. Consequently, the asymmetric information is disadvantageous for market competitiveness and consumer welfare, because it always negatively influences the pricing strategy of the low-carbon supply chain.

In Figure 1 , Domain $\mathrm{E}$ is surrounded by $\lambda=1, \beta=1$, and $\lambda\left(\lambda \beta^{3}+\lambda \beta^{2}+3 \lambda \beta+2 \beta-\lambda-2\right)=1$, where the parameters $\lambda$ and $\beta$ respectively denote the fairness intensity and probability of F-type fall in the interval from 0 to 1 . In Domain E, the fairness intensity is relatively strong, and the probability of F-type is relatively big, which means that the unfair distribution is concerned not only heavily, but also regularly.

In summary, the interactive impacts between the fairness concerns and asymmetric information are stable and smooth at the systematic level, although the impact of either fairness concerns or asymmetric information changes with the behavioural type and information structure randomly at the individual level.

\subsection{On Emission Reducing Strategy}

6.2.1. Individual Level. The manufacturer decides the optimal degree of carbon emission reduction. Proposition 2 and Proposition 5 give the results of individual decision under symmetric and asymmetric information, respectively. By comparing them, illustrate the change of emission- 


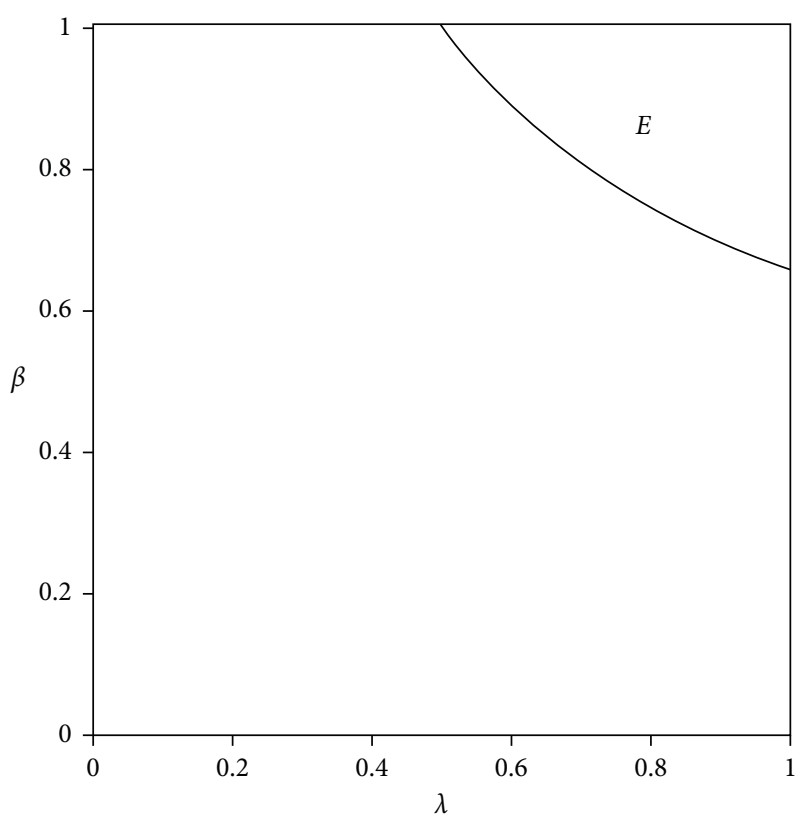

Figure 1: Domain E.

reducing strategy resulting from asymmetric information at the level of individual decision as follows.

Theorem 3. $e_{f}^{*}<\bar{e}^{*}<e_{s}^{*} ; \partial\left(\bar{e}^{*}-e_{f}^{*}\right) / \partial \lambda>0, \partial\left(e_{s}^{*}-\bar{e}^{*}\right) / \partial \lambda$ $>0$.

The manufacturer sets a single moderate degree of carbon emission reduction under asymmetric information, which is lower than that for the S-type retailer under symmetric information and higher than that for the F-type retailer under symmetric information. Moreover, both the gap between the single moderate degree of carbon emission reduction under asymmetric information and that for the S-type retailer under symmetric information and the gap between the single moderate degree of carbon emission reduction under asymmetric information and that for the F-type retailer under symmetric information increase with the fairness intensity. In brief, the bigger the fairness intensity, the more the asymmetric information changing the individual decision of carbon emission reduction.

6.2.2. Systematic Level. In the scenario of symmetric information, the manufacturer can observe the behavioural type of the retailer and thereby depend the degree of carbon emission reduction on the behavioural type of the retailer, denoted as $e_{f}^{*}$ and $e_{s}^{*}$ given in Proposition 2, where the probability is $\beta$ and $1-\beta$ respectively. Taking the low-carbon supply chain as an entire system, the average degree of carbon emission reduction under symmetric information is $e_{A}^{*}=\beta e_{f}^{*}+(1-\beta) e_{s}^{*}$ systematically.

In the scenario of asymmetric information, the manufacturer cannot observe the behavioural type of the retailer and thereby has to decide a uniform degree of carbon emission reduction $\bar{e}^{*}$ given in Proposition 5, which is independent on the behavioural preference of the retailer although the probability of F-type and S-type is still $\beta$ and $1-\beta$. Taking the low-carbon supply chain as an entire system, the degree of carbon emission reduction under asymmetric information is $e_{A}^{*}=\bar{e}^{*}$ still, which is a certain value instead of the expected value.

The difference between the above two scenarios describes the impact of the asymmetric information on the carbon emission-reducing strategy at the level of systematically operational performance.

Theorem 4. $\bar{e}_{A}^{*}>e_{A}^{*} ; \partial\left(\bar{e}_{A}^{*}-e_{A}^{*}\right) / \partial \lambda>0$, with the exception of Domain E.

Systematically, the asymmetric information enhances the average degree of carbon emission reduction of the low-carbon supply chain. The bigger the fairness intensity, the more the attention paid to the unfair distribution, and the more the enhancements with a tiny exception. In the perspective of market, the asymmetric information increases the competitiveness of the low-carbon supply chain because of more carbon emission reduction. In the perspective of consumers, the asymmetric information increases their welfare, because they only need to pay the same for the more environmentally friendly products. In the perspective of environmental protection, the asymmetric information can accelerate reducing carbon emissions. Consequently, the asymmetric information is advantageous for market competitiveness, consumer welfare, and environmental sustainability, because it always positively promotes the degree of carbon emission reduction.

\subsection{On Profitability}

6.3.1. Individual Level. Proposition 3 gives the manufacturer's profit and the retailer's profit, respectively, under symmetric information, and Proposition 6 gives those under asymmetric information. By comparing them one by one, illustrate the impact of the asymmetric information on the profitability at the level of individual decision as follows.

Theorem 5. $\bar{\pi}_{m s}^{*}<\pi_{m s}^{*}, \quad \partial\left(\pi_{m s}^{*}-\bar{\pi}_{m s}^{*}\right) / \partial \lambda>0 ; \quad \bar{\pi}_{m f}^{*}>\pi_{m f}^{*}$, $\partial\left(\bar{\pi}_{m f}^{*}-\pi_{m f}^{*}\right) / \partial \lambda>0 . \bar{\pi}_{r s}^{*}>\pi_{r s}^{*} ; \partial\left(\bar{\pi}_{r s}^{*}-\pi_{r s}^{*}\right) / \partial \lambda>0 . \bar{\pi}_{r f}^{*}<\pi_{r f}^{*}$; $\partial\left(\pi_{r f}^{*}-\bar{\pi}_{r f}^{*}\right) / \partial \lambda>0$.

Firstly, the manufacturer gains lower profit when cooperating with an S-type retailer under asymmetric information than that under symmetric information; meanwhile, he gains higher profit when cooperating with an F-type retailer under asymmetric information than that under symmetric information, and both gaps increase with the fairness intensity. Under symmetric information, the manufacturer can observe the behavioural type of the retailer and thereby know what type of retailer he is cooperating with. However, under symmetric information, the manufacturer cannot observe the behavioural type of the retailer and thereby supposes that the retailer may be S-type with probability $1-\beta$, and F-type with probability $\beta$. No matter he is in fact cooperating with an S-type retailer or F-type retailer, the manufacturer always thinks so because he cannot observe the behavioural type. Such misperception from 
asymmetric information makes the manufacturer earn less profit under asymmetric information than that under symmetric information when the cooperating retailer is S-type but earns more profit when the cooperating retailer is F-type, and both gaps increase with fairness intensity.

Secondly, the S-type retailer achieves higher profits under asymmetric information than that under symmetric information. Moreover, the stronger the fairness intensity, the more the attention paid to the unfair distribution, the wider the gap between those under symmetric and asymmetric information, and the more the asymmetric information changing the S-type retailer's profit.

Thirdly, the F-type retailer achieves lower profits under asymmetric information than that under symmetric information individually. Moreover, the stronger the fairness intensity, the more the attention paid to the unfair distribution, the wider the gap between those under symmetric and asymmetric information, and the more the asymmetric information changing the F-type retailer's profit also.

Comparing the latter two cases, the impact of asymmetric information on the retailer's profit is up to the concrete behavioural type of the retailer. The asymmetric information will make the S-type retailer achieve higher but make the F-type retailer achieve lower profits, although only the F-type retailer suffers disutility from unfair distribution.

Summarily, how the fairness concerns influence the profit of each member changes with the behavioural type and information structure randomly. It appears analogous in case of asymmetric information.

6.3.2. Systematic Level. In the scenario of symmetric information, Proposition 3 gives the manufacturer's profit and the retailer's profit. Taking the low-carbon supply chain as an entire system, the average profit of the manufacturer at the level of systematically operational performance under symmetric information is $\pi_{m A}^{*}=\beta \pi_{m f}^{*}+(1-\beta) \pi_{m s}^{*}$, that of the retailer is $\pi_{r A}^{*}=\beta \pi_{r f}^{*}+(1-\beta) \pi_{r s}^{*}$, and that of the supply chain is $\pi_{t A}^{*}=\pi_{m A}^{*}+\pi_{r A}^{*}$ respectively.

In the scenario of asymmetric information, Proposition 6 gives the manufacturer's profit and the retailer's profit. Taking the low-carbon supply chain as an entire system, the average profit of the manufacturer at the level of systematically operational performance under asymmetric information is $\bar{\pi}_{m A}^{*}=\beta \bar{\pi}_{m f}^{*}+(1-\beta) \bar{\pi}_{m s}^{*}$, that of the retailer is $\bar{\pi}_{r A}^{*}=\beta \bar{\pi}_{r f}^{*}+(1-\beta) \bar{\pi}_{r s}^{*}$, and that of the supply chain is $\bar{\pi}_{t A}^{*}=\bar{\pi}_{m A}^{*}+\bar{\pi}_{r A}^{*}$.

The difference between the above two scenarios describes the impact of the asymmetric information on the profitability at the level of systematically operational performance.

Theorem 6. $\bar{\pi}_{m A}^{*}>\pi_{m A}^{*} ; \partial\left(\bar{\pi}_{m A}^{*}-\pi_{m A}^{*}\right) / \partial \lambda>0$, with the exception of Domain E. $\bar{\pi}_{r A}^{*}<\pi_{r A}^{*} ; \quad \partial\left(\pi_{r A}^{*}-\bar{\pi}_{r A}^{*}\right) / \partial \lambda>0$. $\bar{\pi}_{t A}^{*}<\pi_{t A}^{*} ; \partial\left(\pi_{t A}^{*}-\bar{\pi}_{t A}^{*}\right) / \partial \lambda>0$.

Systematically, the asymmetric information enhances the manufacturer's profit but cuts the retailer's profit. The impact on the retailer's profit dominates that on the manufacturer's profit. Thus, the asymmetric information always decreases the profit of the supply chain. The bigger the fairness intensity, the more the impact with exception of the manufacturer's profit in case of extremely heavy and regular attention paid to unfair distribution. In the perspective of market, the asymmetric information cuts the profit of the supply chain and thereby decreases the competitiveness of the low-carbon supply chain, which is consistent with the result of enhancing price illustrated in Theorem 2. In the perspective of sustainable investment, the asymmetric information is negative, because it cuts the manufacturer's profit, which is the basis of applying environmental technology to reduce emissions.

\section{Case Study}

7.1. Low-Carbon Policy of SAIC Motor. As the largest carmaker in China, SAIC Motor ranked 60th on the latest Fortune Global 500 list reported on August 2, 2021. The vision of SAIC is to provide an exciting ride for a green and intelligent future. At the World New Energy Vehicle Conference 2021, Mrs. Wang, CEO of SAIC Motor, said that SAIC would strive to reach the carbon peak by 2025. In order to realize the goal of achieving carbon peak by 2025, SAIC will implement a series of policies, which involve low carbonizing at each stage of the supply chain.

Firstly, at the stage of suppliers, SAIC requires all the upstream enterprises of automobile parts, including power drive systems, chassis, interior and exterior trims, batteries, electric drives, power electronics, and so on, to carry out the low-carbon strategy and submit the report on the carbon footprint of products to the downstream vehicle enterprises. The auto companies have been breaking the traditional boundaries to expand and reshape industrial ecology. SAIC cooperates with NVIDIA, TT Tech, Huawei, and Mobileye, to form systematic solutions, which ensure a fair responsibility of carbon emission reduction.

Secondly, at the stage of manufacturers, SAIC plans to increase the total amount of green electricity produced itself, enhance the proportion of using clean energy, and improve carbon emission reduction in the process of production. In 2021, SAIC launches a new-generation electric battery system with improved high efficiency of energy conversion and carries out more than 70 projects, which can save per year 24000 tons of standard coal, that is, reducing 1\% carbon emission. SAIC plans to apply a solid-state lithium battery with high energy density into commercial operation by 2025 .

Thirdly, at the stage of end-users, SAIC plans to accelerate resource recovery and resource recycling and explores a new business model of smart travel advantageous for energy saving and carbon emission reduction. Since 2020, SAIC has been piloting and sharing data with users to improve the user experiences of IM Motors founded by SAIC and Alibaba jointly.

Integrating the above three stages of the supply chain, SAIC has established a series of efficient low-carbon policies of emission reduction. In 2020, SAIC sold 5.6 million vehicles, where 2.6 million, 46.4 percent, were self-branded, 0.32 million new energy vehicles, and 0.39 million exported vehicles, in 2021, 8 million vehicles, a year-on-year increase of 42.9 percent. 
To illustrate and verify the theoretical findings, standardize all the real data. According to the configuration and assumptions of the above model, specify the parameters as follows. The potential market demand is standardized as $a=50$, low-carbon sensitivity as $\theta=0.2$, unit production cost as $c=1$, marginal sustainable coefficient as $k=20$, probability of F-type as $\beta=0.4$, and the fairness intensity $\lambda$ which measures how much the unfair distribution is concerned changes in the interval from 0 to 1 freely. With the standardized numerical parameters, the optimal price, degree of carbon emission reduction, and profits can be gotten according to the above theoretic propositions, corollaries, and theorems. Then, analyze their sensitivities to fairness concerns, that is, how they change with the fairness intensity under symmetric and asymmetric information, respectively.

7.2. Sensitivity to Fairness Concerns. The following makes the sensitivity analysis at the systematic level. The results at the individual level always depend on the behavioural type and thereby change randomly; meanwhile, those at the systematic level are irrelated with the behavioural type and change smoothly. Thus, it is reasonable to adopt the systematic level to illustrate the sensitivity of the low-carbon supply chain's operational performance to fairness concerns.

7.2.1. Sensitivity of Price. With the above numerical parameters, the optimal pricing strategy under symmetric information is obtained by Proposition 1, and that under asymmetric information by Proposition 4. Figure 2 shows the sensitivity of systematic wholesale price and retail price to fairness concerns, respectively. Although the curve describing the wholesale price looks like that of the retail price very much, the ordinate scale of the wholesale price is from 21 to 26 ; meanwhile, that of retail price falls in a much narrower interval between 37.765 and 37.769. Therefore, there is a big difference actually.

Firstly, the impact of fairness intensity: no matter under symmetric or asymmetric information, both the wholesale price and the retail price decrease with the fairness intensity, which is illustrated in Corollary 1 . Moreover, the impact of fairness intensity on the retail price is very much small, and thereby the retail price hardly changes with fairness intensity, which Corollary 1 does not capture.

Secondly, the impact of asymmetric information: both the wholesale price and the retail price under asymmetric information must be higher than those under symmetric information, and the difference increases with the fairness intensity, which is illustrated in Theorems 1 and 2. Furthermore, the impact of asymmetric information on the retail price is small very much, and thereby the retail price under symmetric information nearly equals that under asymmetric information, which Theorems 1 and 2 do not discover.

Consequently, beyond verifying the theoretic conclusions of Corollary 1, Theorems 1 and 2, the sensitivity analysis of Figure 2 reaches the following finding.
Observation 1. The fairness concerns decrease the wholesale price of the low-carbon supply chain significantly, but the asymmetric information increases substantially. However, both the fairness concerns and the asymmetric information hardly affect the retail price of the low-carbon supply chain, by which the retail price at the systematic level nearly is kept as a constant no matter under symmetric or asymmetric information.

7.2.2. Sensitivity of Emission Reduction. With the above numerical parameters, the optimal degree of carbon emission reduction under symmetric information is obtained by Proposition 2, and that under asymmetric information by Proposition 5. Figure 3 shows the sensitivity of systematic carbon emission reduction to fairness concerns.

Firstly, the impact of fairness intensity: no matter under symmetric or asymmetric information, the optimal degree of carbon emission reduction decreases with the fairness intensity, which is illustrated in Corollary 2. Moreover, the impact of fairness intensity on the carbon emission reduction becomes smaller and smaller as the fairness intensity approaches to the upper limit gradually, which Corollary 2 does not capture.

Secondly, the impact of asymmetric information: the degree of carbon emission reduction under asymmetric information must be higher than that under symmetric information, and the difference increases with the fairness intensity, which is illustrated in Theorems 3 and 4 .

Consequently, beyond verifying the theoretic conclusions of Corollary 2 and Theorems 3 and 4, the sensitivity analysis of Figure 3 achieves the following finding.

Observation 2. The fairness concerns significantly prevent the carbon emission reduction of the low-carbon supply chain, but the asymmetric information accelerates it dramatically.

7.2.3. Sensitivity of Profitability. With the above numerical parameters, obtain the profit of the manufacturer, that of the retailer, and that of the supply chain under symmetric information by Proposition 3, and those under asymmetric information by Proposition 6. Figure 4 shows their sensitivity to fairness concerns. The ordinate scale of the manufacturer's profit is from 250 to 310 , that of the retailer's profit is between 140 and 200, and that of the supply chain's profit falls in a very narrow interval between 449 and 450.6 , which means that the over profit of the entire supply chain hardly changes with the fairness intensity.

Firstly, the impact of fairness intensity: no matter under symmetric or asymmetric information, the profit of the manufacturer and that of the supply chain decrease with the fairness intensity, but that of the retailer increases, which is illustrated in Corollary 3. Moreover, the impact of fairness intensity on the overall profit of the supply chain is small very much and nearly can be ignored; that is, the overall profit of the supply chain hardly changes with fairness intensity and thereby almost stays as a constant, which is not captured by Corollary 3 at all. 


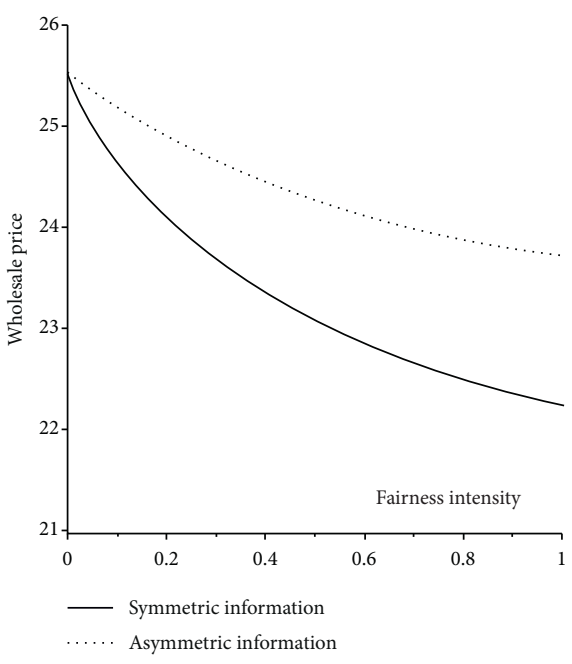

(a)

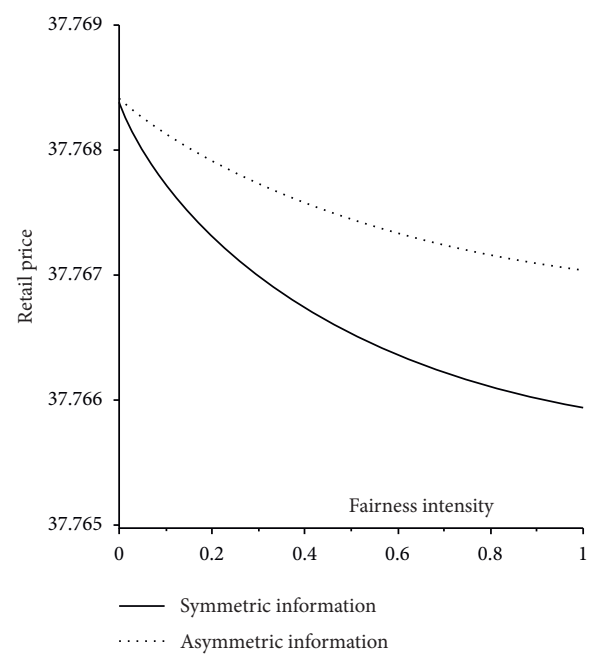

(b)

FIGURE 2: Sensitivity of price to fairness concerns. (a) Wholesale price. (b) Retail price.

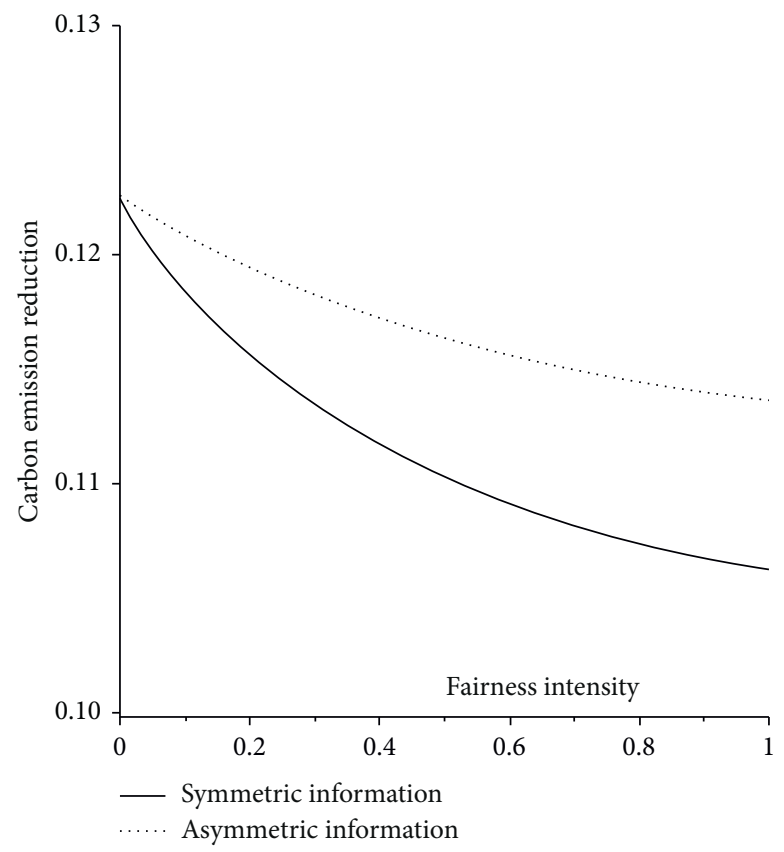

FIGURE 3: Sensitivity of carbon emission reduction to fairness concerns.

Secondly, the impact of asymmetric information: the profit of the manufacturer under asymmetric information must be higher than that under symmetric information, but the profit of the retailer under asymmetric information must be lower than that under symmetric information, which is illustrated in Theorems 5 and 6 . The profit of the supply chain under asymmetric information is very slightly smaller than and approximately equals that under symmetric information, which Theorems 5 and 6 do not capture.

Consequently, beyond verifying the theoretic conclusions of Corollary 3, Theorems 5 and 6 , the sensitivity analysis of Figure 4 reaches the following finding.
Observation 3. Both the fairness concerns and asymmetric information influence the total quantity of the overall profit slightly but change the profit distribution of the overall profit substantially despite being in opposite directions. The fairness concerns decrease the profit of the manufacturer but increase the profit of the retailer significantly, which leads to a fairer distribution within the low-carbon supply chain. However, the asymmetric information increases the profit of the manufacturer but decreases the profit of the retailer dramatically, which results in a less fair distribution within the low-carbon supply chain. 


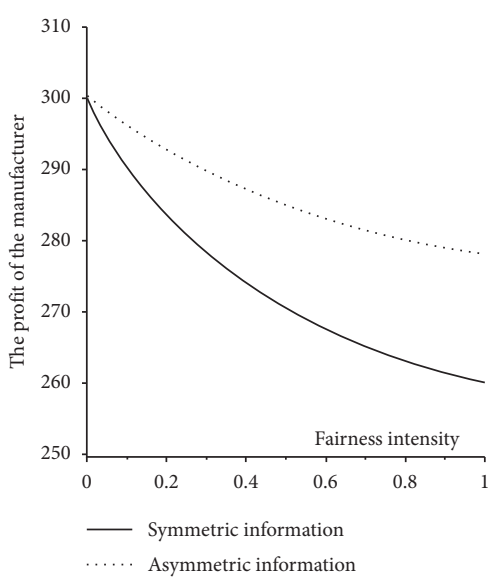

(a)

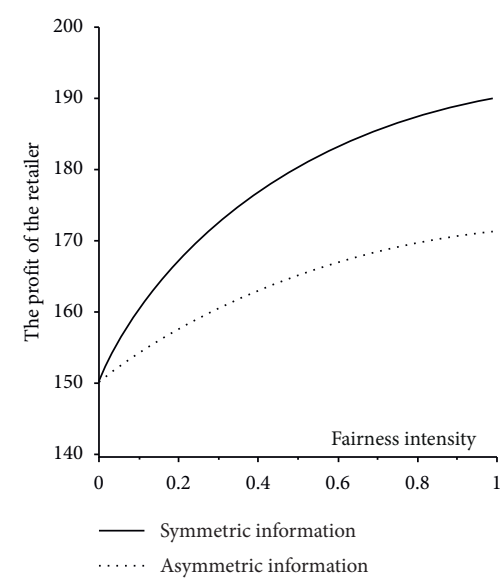

(b)

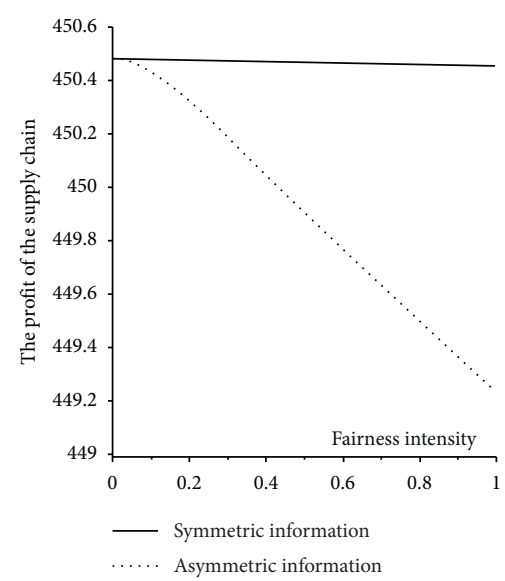

(c)

FIGURE 4: Sensitivity of profitability to fairness concerns. (a) Manufacturer's profit. (b) Retailer's profit. (c) Supply chain's profit.

\section{Conclusion}

8.1. Concluding Results. This paper achieves the optimal operational strategy of the low-carbon supply chain under asymmetric information of fairness concerns and analyzes the impacts stemming from the asymmetric information of fairness concerns at the individual and systematic levels, respectively. The main findings include the following.

Firstly, regarding the carbon emission-reducing strategy, the asymmetric information of fairness concerns enhances the carbon emission reduction significantly at the level of systematic operation, whose increment usually increases with the fairness intensity. Specifically, at the level of individual decision, the effect of fairness concerns on the carbon emission reduction is irrelevant with the information structure, but the effect of asymmetric information is up to the behavioural type. The fairness concerns will decrease the carbon emission reduction no matter under symmetric or asymmetric information, while the asymmetric information will increase that for the F-type retailer but decrease that for the S-type retailer. However, previous literature has been holding that fairness concerns always decrease the carbon emission reduction, because it neither neglected the effect of asymmetric information nor distinguished the impacts from asymmetric information and that from fairness concerns. The above findings show that the effect of fairness concerns is different from that of asymmetric information totally, and furthermore, the effect of asymmetric information dominates that of the fairness concerns. Therefore, incorporating the asymmetric information of fairness concerns can implement and correct the common conclusion in extant literature.

Secondly, regarding the pricing strategy, the asymmetric information of fairness concerns raises the wholesale price and retail price significantly at the level of systematic operation, whose increment usually increases with the fairness intensity. Specifically, at the level of individual decision, the fairness concerns cut down the wholesale price no matter under symmetric or asymmetric information and decrease the retail price under symmetric information but increase under asymmetric information no matter whatever behavioural type. The asymmetric information raises both the wholesale price and retail price in the case of the F-type retailer but cut down that in the case of the S-type retailer. Although the impact of either fairness concerns or asymmetric information at the individual level depends on the behavioural type and information structure and thereby changes randomly, their interactions at the systematic level are stably smooth. However, previous literature has been holding that fairness concerns always cut down the wholesale price and retail price, which is on the complete opposite, because it ignored the asymmetric information of fairness concerns. The above findings show that the fairness concerns and asymmetric information influence the pricing strategy in different ways, and the impact of asymmetric information is the dominant power. Therefore, it is necessary to incorporate the asymmetric information of fairness concerns, which in fact can revise the widely adopted conclusion in previous literature.

Thirdly, regarding the profitability, the asymmetric information of fairness concerns achieves a fairer profit distribution, while either fairness concerns or asymmetric information hardly changes the overall profit at the level of systematic operation. Specifically, at the level of individual decision, their impacts almost depend on the behavioural type. The fairness concerns decrease the manufacturer's profit no matter under symmetric or asymmetric information and increase the retailer's profit under symmetric information but decreases under asymmetric information. The asymmetric information increases the profit of the manufacturer cooperating with an F-type retailer but decreases in the case of S-type, while increasing the profit of the S-type retailer but decreasing in the case of F-type. However, previous literature has been dealing with the individual level and hardly touched the systematic level with the exception of overall profit. At the level of individual decision, results always depend on the behavioural type, which changes randomly with a probability distribution. At the level of systematic operation, results are irrelated with the behavioural type and change smoothly. Therefore, adoption of the 
systematic level is useful for discovering the essential principles, which almost did not occur in previous literature.

8.2. Managerial Implications. From the above findings, conclude some managerial implications for supply chain managers as follows.

Firstly, supply chain managers need to incorporate properly the asymmetric information of fairness concerns, which can ensure a rational operational strategy of the lowcarbon supply chain. The purely selfish preference in classical supply chain literature will lead to decision bias, because the fairness concerns have different impacts. The fairness concerns in behavioural supply chain literature also will result in decision bias, because the asymmetric information has different impacts also, as shown by experimental evidence. The behavioural type is private information. Only under the real condition of asymmetric information of fairness concerns can supply chain managers plan and implement the operational strategy reasonably.

Secondly, supply chain managers need to predict the information on the behavioural type and intensity of supply chain partners promptly and precisely, which is useful for facilitating the rational carbon emission-reducing strategy. The precise prediction of the behavioural type and relevant intensity and updating the information promptly can ensure rational decisions dynamically. Both the internal information management and the external information from suppliers, consulting agencies, customers, banks, etc., can help improve the accuracy of the prediction about the behavioural type and relevant intensity, which can reduce the information losses from behavioural asymmetry and enhance the profitability.

Finally, supply chain managers need to apply smart information technology into the decision of carbon emission-reducing strategy, which can alleviate the behavioural asymmetry. Under asymmetric information, the behavioural type and relevant intensity are private information. Supply chain partners may use the private information of the behavioural type and relevant intensity strategically, which makes the behavioural asymmetry more serious. Smart information technology can prevent stored information from being modified and help diminish misreported information. In the long term, smart information management can avoid losses from behavioural asymmetry, bigger than its implemented costs.

8.3. Future Scope. Three issues are worth mentioning for future scope. Firstly, the low-carbon supply chain consisting of multiple competing retailers should be considered. There are always multiple retailers in practice, but the paper only models the case including one manufacturer and one retailer. Secondly, different power structures of the low-carbon supply chain should be considered. There are three kinds of power structures in practice, that is, manufacturer dominating structure, retailer dominating structure, and Nash vertical structure, but the paper only models the case of manufacturer dominating structure. Thirdly, operational strategy adopting sorted mechanism should be considered. There are two kinds of mechanism in scenario of asymmetric information as discussed by Wei et al. (2019), that is, sorted mechanism and pooled mechanism, but the paper only adopts the case of pooled mechanism.

\section{Appendix}

Proof of Theorem 1. Firstly, from $w_{s}^{*}=2 k(a+c)-\theta^{2} c$ $/ 4 k-\theta^{2}, \quad w_{f}^{*}=-c \lambda \theta^{2}+2 a k \lambda+6 c k \lambda-c \theta^{2}+2 a k+2 c k \quad / 4 k$ $(2 \lambda+1)-\theta^{2}(1+\lambda)$, and.

$$
\bar{w}^{*}=c \lambda k\left(4 \beta^{2}+2\right)+2 a \lambda k+2 k(a+c)-c \theta^{2}(1+\lambda) / 4 k+
$$

$4 \lambda k\left(\beta^{2}+1\right)-\theta^{2}(1+\lambda)$, it can be calculated that

$$
\begin{aligned}
w_{s}^{*}-\bar{w}^{*} & =\frac{8 \lambda \beta^{2} k^{2}(a-c)}{\left(4 k-\theta^{2}\right)\left(4 k+4 \lambda k+4 \lambda k \beta^{2}-\theta^{2}-\lambda \theta^{2}\right)}, \\
\frac{\partial\left(w_{s}^{*}-\bar{w}^{*}\right)}{\partial \lambda} & =\frac{8 \beta^{2} k^{2}(a-c)}{\left(4 k+4 \lambda k+4 \lambda k \beta^{2}-\theta^{2}-\lambda \theta^{2}\right)^{2}}, \\
\bar{w}^{*}-w_{f}^{*} & =\frac{8 \lambda k^{2}(1-\beta)(1+\beta)(1+\lambda)(a-c)}{\left(4 k+8 \lambda k-\theta^{2}-\lambda \theta^{2}\right)\left(4 k+4 \lambda k+4 \lambda k \beta^{2}-\theta^{2}-\lambda \theta^{2}\right)} .
\end{aligned}
$$

and

$$
\frac{\partial\left(\bar{w}^{*}-w_{f}^{*}\right)}{\partial \lambda}=\frac{8 k^{2}(1-\beta)(1+\beta)(a-c)\left(4 k+4 \lambda k+4 \lambda k \beta-\theta^{2}-\lambda \theta^{2}\right)\left(4 k+4 \lambda k-4 \lambda k \beta-\theta^{2}-\lambda \theta^{2}\right)}{\left(4 k+8 \lambda k-\theta^{2}-\lambda \theta^{2}\right)^{2}\left(4 k+4 \lambda k+4 \lambda k \beta^{2}-\theta^{2}-\lambda \theta^{2}\right)^{2}} .
$$


Because $0<\beta<1,0<\lambda<1, a>c$, and $k$ is sufficiently large, it is clear that $w_{s}^{*}-\bar{w}^{*}>0, \partial\left(w_{s}^{*}-\bar{w}^{*}\right) / \partial \lambda>0$, $\bar{w}^{*}-w_{f}^{*}>0$, and $\partial\left(\bar{w}^{*}-w_{f}^{*}\right) / \partial \lambda>0$.

Secondly, from $p_{s}^{*}=(3 a+c) k-\theta^{2} c / 4 k-\theta^{2}, \bar{p}_{s}^{*}=2 \lambda k \beta^{2}$ $\begin{array}{llll}(a+c)+k & (\lambda+1)(3 a+c)-c \theta^{2}(1+\lambda) & / 4 k\left(\lambda \beta^{2}+\lambda+1\right)\end{array}$ $-\theta^{2}(1+\lambda)$

$$
p_{f}^{*}=(2 \lambda+1)(3 a+c) k-c \theta^{2}(1+\lambda) / 4 k(2 \lambda+1)-\theta^{2}(1
$$
$+\lambda), \bar{p}_{f}^{*}=\lambda k \beta[a(2 \beta+1)+c(2 \beta-1)]+k(1+\lambda)(3 a+c)-$ $c \theta^{2}(1+\lambda) / 4 k\left(\lambda \beta^{2}+\lambda+1\right)-\theta^{2}(1+\lambda)$, it can be calculated that $p_{s}^{*}-\bar{p}_{s}^{*}=2 \lambda k \beta^{2}(a-c)\left(2 k+\theta^{2}\right) /\left(4 k-\theta^{2}\right)(4 k+4 k \lambda$ $\left.+4 k \lambda \beta^{2}-\theta^{2}-\theta^{2} \lambda\right)$,

$$
\begin{aligned}
\frac{\partial\left(p_{s}^{*}-\bar{p}_{s}^{*}\right)}{\partial \lambda} & =\frac{2 k \beta^{2}\left(\theta^{2}+2 k\right)(a-c)}{\left(4 k+4 k \lambda+4 k \lambda \beta^{2}-\theta^{2}-\theta^{2} \lambda\right)^{2}} \\
\bar{p}_{f}^{*}-p_{f}^{*} & =\frac{\lambda k(1-\beta)(a-c)\left(2 \lambda \beta \theta^{2}+8 \lambda \beta k+2 \beta \theta^{2}+3 \lambda \theta^{2}+4 \beta k+3 \theta^{2}\right)}{\left(4 k+8 k \lambda-\theta^{2}-\lambda \theta^{2}\right)\left(4 k+4 k \lambda+4 k \lambda \beta^{2}-\theta^{2}-\lambda \theta^{2}\right)} .
\end{aligned}
$$

Also,

$$
\frac{\partial\left(\bar{p}_{f}^{*}-p_{f}^{*}\right)}{\partial \lambda}=\frac{k(1-\beta)(a-c) A}{\left(4 k+8 k \lambda-\theta^{2}-\lambda \theta^{2}\right)^{2}\left(4 k+4 k \lambda+4 k \lambda \beta^{2}-\theta^{2}-\lambda \theta^{2}\right)^{2}}
$$

where

$$
\begin{aligned}
A= & 64 \beta(1+2 \lambda)^{2} k^{3}-16 \theta^{2}\left(3 \beta^{3} \lambda^{2}+3 \beta^{2} \lambda^{2}+5 \beta \lambda^{2}+4 \beta \lambda-3 \lambda^{2}-6 \lambda-3\right) k^{2}, \\
& -4 \theta^{4}(1+\lambda)(\beta \lambda+3 \beta+6 \lambda+6) k-\theta^{6}\left(2 \beta \lambda^{2}-4 \beta \lambda-3 \lambda^{2}-2 \beta-6 \lambda-3\right) .
\end{aligned}
$$

Because $0<\beta<1,0<\lambda<1, a>c$, and $k$ is sufficiently large, it is clear that $p_{s}^{*}-\bar{p}_{s}^{*}>0$,

$\partial\left(p_{s}^{*}-\bar{p}_{s}^{*}\right) / \partial \lambda>0, \bar{p}_{f}^{*}-p_{f}^{*}>0$, and $\partial\left(\bar{p}_{f}^{*}-p_{f}^{*}\right) / \partial \lambda>0$. Q. E. D.
Proof of Theorem 2. Firstly, by $w_{A}^{*}=\beta w_{f}^{*}+(1-\beta) w_{s}^{*}=\beta-$ $c \lambda \theta^{2}+2 a k \lambda+6 c k \lambda-c \theta^{2}+2 a k+2 c k / 4 k(2 \lambda+1)-\theta^{2}(1+$ $\lambda)+(1-\beta) 2 k(a+c)-\theta^{2} c / 4 k-\theta^{2}$ and $\bar{w}_{A}^{*}=\bar{w}^{*}=c \lambda k\left(4 \beta^{2}\right.$ $+2)+2 a \lambda k+2 k(a+c)-c \theta^{2}(1+\lambda) / 4 k+4 \lambda k\left(\beta^{2}+1\right)-\theta^{2}$ $(1+\lambda)$, it can be calculated that

$$
\begin{aligned}
& \bar{w}_{A}^{*}-w_{A}^{*}=\frac{8 \lambda \beta k^{2}(1-\beta)(a-c)\left[4 k+4 \lambda k(1-\beta)-\theta^{2}-\lambda \theta^{2}\right]}{\left(8 k \lambda+4 k-\theta^{2}-\lambda \theta^{2}\right)\left(4 k+4 \lambda k+4 \lambda k \beta^{2}-\theta^{2}-\lambda \theta^{2}\right)\left(4 k-\theta^{2}\right)}, \\
& \frac{\partial\left(\bar{w}_{A}^{*}-w_{A}^{*}\right)}{\partial \lambda}=\frac{8 \beta k^{2}(1-\beta)(a-c)\left(16 B k^{2}-8 \theta^{2}(1+\lambda)(1+\lambda-\beta \lambda) k+\theta^{4}(1+\lambda)^{2}\right)}{\left(8 k \lambda+4 k-\theta^{2}-\lambda \theta^{2}\right)^{2}\left(4 k+4 \lambda k+4 \lambda k \beta^{2}-\theta^{2}-\lambda \theta^{2}\right)^{2}} .
\end{aligned}
$$

where $B=1+2 \lambda+\lambda^{2}-2 \beta \lambda-3 \beta \lambda^{2}-\beta^{2} \lambda^{2}-\beta^{3} \lambda^{2}$. Because $0<\beta<1,0<\lambda<1, a>c$, and $k$ is
Sufficiently large, it is clear that $\bar{w}_{A}^{*}-w_{A}^{*}>0$ and sign $[\partial$ $\left.\left(\bar{w}_{A}^{*}-w_{A}^{*}\right) / \partial \lambda\right]=\operatorname{sign}(B)$. Therefore, $\quad \partial\left(\bar{w}_{A}^{*}-w_{A}^{*}\right) / \partial \lambda>0$ 
unless $B<0$, which is graphically illustrated as Domain $\mathrm{E}$ in Figure 1.

Secondly, by $p_{A}^{*}=\beta p_{f}^{*}+(1-\beta) p_{s}^{*}=\beta(2 \lambda+1)(3 a+c) k$ $-c \theta^{2}(1+\lambda) / 4 k(2 \lambda+1)-\theta^{2}(1+\lambda)+(1-\beta)(3 a+c) k-\theta^{2} c$ $/ 4 k-\theta^{2}$ and $\bar{p}_{A}^{*}=\beta \bar{p}_{f}^{*}+(1-\beta) \bar{p}_{s}^{*}=c k+3 a k-c \theta^{2}+c \lambda k$
$+3 a k \lambda-c \lambda \theta^{2}+c k \lambda \beta^{2}+3 a k \lambda \beta^{2} / 4 k\left(\lambda \beta^{2}+\lambda+1\right)-\theta^{2}(1+\lambda)$, it can be calculated that $\bar{p}_{A}^{*}-p_{A}^{*}=3 \lambda k \beta \theta^{2}(1-\beta)(a-c)$ $\left[4 k+4 \lambda k(1-\beta)-\theta^{2}-\lambda \theta^{2}\right] /\left(4 k-\theta^{2}\right)\left(8 k \lambda+4 k-\theta^{2}-\lambda \theta^{2}\right)$ $\left(4 k+4 \lambda k+4 \lambda k \beta^{2}-\theta^{2}-\lambda \theta^{2}\right)$, and

$$
\frac{\partial\left(\bar{p}_{A}^{*}-p_{A}^{*}\right)}{\partial \lambda}=\frac{3 \beta k \theta^{2}(1-\beta)(a-c)\left(16 B k^{2}-8 \theta^{2}(1+\lambda)(1+\lambda-\beta \lambda) k+\theta^{4}(1+\lambda)^{2}\right)}{\left(8 k \lambda+4 k-\theta^{2}-\lambda \theta^{2}\right)^{2}\left(4 k+4 \lambda k+4 \lambda k \beta^{2}-\theta^{2}-\lambda \theta^{2}\right)^{2}}
$$

Similarly, $\bar{p}_{A}^{*}-p_{A}^{*}>0, \partial\left(\bar{w}_{A}^{*}-w_{A}^{*}\right) / \partial \lambda>0$ unless $B<0$ illustrated as Domain E in Figure 1. Q. E. D.

Proof of Theorem 3. From $e_{s}^{*}=\theta(a-c) / 4 k-\theta^{2}, e_{f}^{*}=\theta(a-$ c) $(1+\lambda) / 4 k(2 \lambda+1)-\theta^{2}(1+\lambda)$ and $\bar{e}^{*}=\theta(1+\lambda)(a-c)$ $/ 4 k+4 \lambda k\left(\beta^{2}+1\right)-\theta^{2}(1+\lambda)$, there are $e_{s}^{*}-\bar{e}^{*}=4 \theta \lambda k$ $\beta^{2}(a-c) /\left(4 k-\theta^{2}\right)\left(4 k+4 \lambda k\left(\beta^{2}+1\right)-\theta^{2}(1+\lambda)\right)>0, \partial\left(e_{s}^{*}\right.$ $\left.-\bar{e}^{*}\right) / \partial \lambda=4 \theta k \beta^{2}(a-c) /\left(4 k+4 \lambda k\left(\beta^{2}+1\right)-\theta^{2}(1+\lambda)\right)^{2}>0$, $\bar{e}^{*}-e_{f}^{*}=4 \theta \lambda k(1+\lambda)(a-c)(1-\beta)(1+\beta) /\left(4 k+4 \lambda k \quad\left(\beta^{2}\right.\right.$ $\left.+1)-\theta^{2}(1+\lambda)\right)\left(4 k(2 \lambda+1)-\theta^{2}(1+\lambda)\right)>0$, and $\partial\left(\bar{e}^{*}-e_{f}^{*}\right)$ $/ \partial \lambda=4 \theta k(a-c)(1-\beta)(1+\beta)\left(4 k+4 k \lambda-4 \lambda k \beta-\lambda \theta^{2}-\theta^{2}\right)$ $\left(4 \lambda k \beta+4 k \lambda+4 k-\lambda \theta^{2}-\theta^{2}\right) /\left(4 k+4 \lambda k\left(\beta^{2}+1\right) \quad-\theta^{2}(1\right.$ $+\lambda))^{2}\left(4 k(2 \lambda+1)-\theta^{2}(1+\lambda)\right)^{2}>0$ because D.

$0<\beta<1,0<\lambda<1, a>c$, and $k$ is sufficiently large. Q. $E$.

Proof of Theorem 4. From $e_{s}^{*}=\theta(a-c) / 4 k-\theta^{2}, e_{f}^{*}=\theta(a-$ c) $(1+\lambda) / 4 k(2 \lambda+1)-\theta^{2}(1+\lambda)$ and $\bar{e}^{*}=\theta(1+\lambda)(a-c)$ $14 k+4 \lambda k\left(\beta^{2}+1\right)-\theta^{2}(1+\lambda)$, there are $\bar{e}^{*}-e^{*}=\bar{e}^{*}-((1-$ $\left.\beta) e_{s}^{*}-\beta e_{f}^{*}\right)=4 \theta \beta k \lambda(a-c)(1-\beta)\left(4 k+4 k \lambda-4 k \lambda \beta-\lambda \theta^{2}-\right.$ $\left.\theta^{2}\right)^{2} /\left(4 k-\theta^{2}\right)\left(4 k+4 \lambda k\left(\beta^{2}+1\right)-\theta^{2} \quad(1+\lambda)\right)(4 k(2 \lambda+1)$ $\left.-\theta^{2}(1+\lambda)\right)>0$, and $\partial\left(\bar{e}^{*}-e^{*}\right) / \partial \lambda=4 \theta \beta k(a-c)(1-\beta)$ $\left(16 B k^{2}+8 \theta^{2}(1+\lambda)(1+\lambda-\beta \lambda) k-\theta^{4}(1+\lambda)^{2}\right) /(4 k+4 \lambda k$ $\left.\left(\beta^{2}+1\right)-\theta^{2}(1+\lambda)\right)^{2}\left(4 k(2 \lambda+1)-\theta^{2}(1+\lambda)\right)^{2}$, in which also $B=1+2 \lambda+\lambda^{2}-2 \beta \lambda-3 \beta \lambda^{2}-\beta^{2} \lambda^{2}-\beta^{3} \lambda^{2}$. Because $0<\beta<1,0<\lambda<1, a>c$, and $k$ is sufficiently large, it is clear that $\bar{e}^{*}-e^{*}>0$ and $\operatorname{sign}\left[\partial\left(\bar{e}^{*}-e^{*}\right) / \partial \lambda\right]=\operatorname{sign}(B)$. Therefore, $\partial\left(\bar{e}^{*}-e^{*}\right) / \partial \lambda>0$ unless $B<0$, which is graphically illustrated as Domain E in Figure 1. Q. E. D.

Proof of Theorem 5. Firstly, from $\pi_{m s}^{*}=k(a-c)^{2} / 8 k-2 \theta^{2}$, $\bar{\pi}_{m s}^{*}=k(1+\lambda)(a-c)^{2} \quad\left(8 k \lambda \beta^{2}+4 k \lambda+4 k-\lambda \theta^{2}-\theta^{2}\right) / 2[4 k$ $\left.\left(\lambda \beta^{2}+\lambda+1\right)-(\lambda+1) \theta^{2}\right]^{2}, \quad \pi_{m f}^{*}=k(\lambda+1)(a-c)^{2} \quad / 2 \lambda$ $\left(8 k-\theta^{2}\right)+8 k-2 \theta^{2}$, and $\bar{\pi}_{m f}^{*}=k(1+\lambda) \quad(a-c)^{2}\left(8 k \lambda \beta^{2}\right.$ $\left.-4 k \lambda \beta+4 k \lambda+4 k-\lambda \theta^{2}-\theta^{2}\right) / 2\left[4 k\left(\lambda \beta^{2}+\lambda+1\right)-(\lambda+1)\right.$ $\left.\theta^{2}\right]^{2}$, there are $\pi_{m s}^{*}-\bar{\pi}_{m s}^{*}=8 \lambda^{2} k^{3} \beta^{4}(a-c)^{2} / 2\left(4 k-\theta^{2}\right)$ $\left[4 k\left(\lambda \beta^{2}+\lambda+1\right)-(\lambda+1) \theta^{2}\right]^{2}>0, \quad \partial\left(\pi_{m s}^{*}-\bar{\pi}_{m s}^{*}\right) \quad / \partial \lambda$ $=16 \lambda k^{3} \beta^{4}(a-c)^{2} /\left[4 k\left(\lambda \beta^{2}+\lambda+1\right)-(\lambda+1) \theta^{2}\right]^{3}>0$,

$$
\bar{\pi}_{m f}^{*}-\pi_{m f}^{*}=\frac{2 \lambda k^{2}(1+\lambda)(1-\beta)(a-c)^{2}\left(4 k \lambda \beta^{3}+4 k \lambda \beta^{2}-4 k \lambda \beta+4 k \lambda+4 k-\lambda \theta^{2}-\theta^{2}\right)}{\left[4 k\left(\lambda \beta^{2}+\lambda+1\right)-(\lambda+1) \theta^{2}\right]^{2}\left[2 \lambda\left(8 k-\theta^{2}\right)+8 k-2 \theta^{2}\right]}>0,
$$

$\partial\left(\bar{\pi}_{m f}^{*}-\pi_{m f}^{*}\right) / \partial \lambda=2 k^{2}(1-\beta)(a-c)^{2} F /\left[4 k\left(\lambda \beta^{2}+\lambda+1\right)\right.$ $\left.-(\lambda+1) \theta^{2}\right]^{3}\left[2 \lambda\left(8 k-\theta^{2}\right)+8 k-2 \theta^{2}\right]^{2}>0$, where $F=64 G k^{3}$ $+\cdots>0, G=1+3 \lambda+3 \lambda^{2}-2 \beta \lambda+\lambda^{3}-5 \beta \lambda^{2}+\beta^{2} \lambda-3 \beta \lambda^{3}+$ $\beta^{2} \lambda^{2}+2 \beta^{3} \lambda+5 \beta^{3} \lambda^{2}+4 \beta^{3} \lambda^{3}-\beta^{4} \lambda^{3}-\beta^{5} \lambda^{3}>0$ because $0<\beta$ $<1,0<\lambda<1, a>c$, and $k$ is sufficiently large.

Secondly, by $\pi_{r s}^{*}=k^{2}(a-c)^{2} /\left(4 k-\theta^{2}\right)^{2}, \quad \pi_{r f}^{*}=k^{2}$ $(a-c)^{2}(4 \lambda+1)(2 \lambda+1) /\left(4 k-\theta^{2}+\lambda\left(8 k-\theta^{2}\right)\right)^{2}, \quad \bar{\pi}_{r s}^{*}=k^{2}$ $(a-c)^{2}\left(2 \lambda \beta^{2}+\lambda+1\right)^{2} /\left[4 k\left(\lambda \beta^{2}+\lambda+1\right)-(\lambda+1) \theta^{2}\right]^{2}$, and $\bar{\pi}_{r f}^{*}=k^{2}(a-c)^{2}\left(2 \lambda \beta^{2}+\lambda \beta+\lambda+1\right)\left(2 \lambda \beta^{2}-\lambda \beta+\lambda+1\right) /$ $\left[4 k\left(\lambda \beta^{2}+\lambda+1\right)-(\lambda+1) \theta^{2}\right]^{2}$, there are $\bar{\pi}_{r s}^{*}-\pi_{r s}^{*}=4 \lambda k^{2} \beta^{2}$ $(a-c)^{2}\left(2 k-\theta^{2}\right) \quad\left(4 k+4 \lambda k+6 \lambda k \beta^{2}-\beta^{2} \lambda \theta^{2}-\lambda \theta^{2}-\theta^{2}\right)$ $/\left[4 k\left(\lambda \beta^{2}+\lambda+1\right)-(\lambda+1) \theta^{2}\right]^{2}\left(4 k-\theta^{2}\right)^{2}>0, \partial\left(\bar{\pi}_{r s}^{*}-\pi_{r s}^{*}\right)$ $/ \partial \lambda=4 k^{2} \beta^{2}(a-c)^{2}\left(2 k-\theta^{2}\right)\left(2 \lambda \beta^{2}+\lambda+1\right) /\left[4 k\left(\lambda \beta^{2}+\lambda+1\right)\right.$ $\left.-(\lambda+1) \theta^{2}\right]^{3}>0$, and $\bar{\pi}_{r s}^{*}-\bar{\pi}_{r f}^{*}=\lambda k^{2}(a-c)^{2}(1-\beta)(1+\beta) H$ $/\left[4 k\left(\lambda \beta^{2}+\lambda+1\right)-(\lambda+1)\right.$

$\left.\theta^{2}\right]^{2}\left[4 k\left(\lambda \beta^{2}+\lambda+1\right)-(\lambda+1) \theta^{2}\right]^{2}>0$, where

$$
H=16\left(8 \beta^{2} \lambda^{3}+10 \beta^{2} \lambda^{2}+3 \beta^{2} \lambda+4 \lambda^{3}+10 \lambda^{2}+8 \lambda+2\right) k^{2}+\cdots>0
$$

$\partial\left(\bar{\pi}_{r s}^{*}-\bar{\pi}_{r f}^{*}\right) / \partial \kappa=-2 k^{2}(a-c)^{2}(1-\beta)(1+\beta) I /\left[4 k\left(\lambda \beta^{2}\right.\right.$ $\left.+\lambda+1)-(\lambda+1) \theta^{2}\right]^{3}\left[4 k\left(\lambda \beta^{2}+\lambda+1\right)-(\lambda+1) \theta^{2}\right]^{3}>0$, in which $I=256\left(2 \beta^{4} \lambda^{4}+\beta^{4} \lambda^{3}-8 \beta^{2} \lambda^{4}-14 \beta^{2} \lambda^{3}-9 \quad \beta^{2} \lambda^{2}-\right.$ $\left.2 \lambda^{4}-2 \beta^{2} \lambda-7 \lambda^{3}-9 \lambda^{2} \quad-5 \lambda-1\right) k^{4}+\cdots<0_{\text {because }} 0<\beta<1$, $0<\lambda<1, a>c$, and $k$ is sufficiently large. Q. E. D.
Proof of Theorem 6. Firstly, from $\pi_{m s}^{*}=k(a-c)^{2} / 8 k-2 \theta^{2}$, $\bar{\pi}_{m s}^{*}=k(1+\lambda)(a-c)^{2}\left(8 k \lambda \beta^{2}+4 k \lambda+4 k-\lambda \theta^{2}-\theta^{2}\right) \quad / 2[4 k$ $\left.\left(\lambda \beta^{2}+\lambda+1\right)-(\lambda+1) \theta^{2}\right]^{2}, \pi_{m f}^{*}=k(\lambda+1)(a-c)^{2} / 2 \lambda(8 k-$ $\left.\theta^{2}\right)+8 k-2 \theta^{2}$, and $\bar{\pi}_{m f}^{*}=k(1+\lambda)(a-c)^{2}\left(8 k \lambda \beta^{2}-4 k \lambda \beta+\right.$ $\left.4 k \lambda+4 k-\lambda \theta^{2}-\theta^{2}\right) / 2\left[4 k\left(\lambda \beta^{2}+\lambda+1\right)-(\lambda+1) \theta^{2}\right]^{2}$, there 
are $\bar{\pi}_{m A}^{*}-\pi_{m A}^{*}=\left(\beta \bar{\pi}_{m f}^{*}+(1-\beta) \bar{\pi}_{m s}^{*}\right)-\left(\beta \pi_{m f}^{*}+(1-\beta) \pi_{m s}^{*}\right)$ $=2 \lambda \beta k^{2}(a-c)^{2}(1-\beta)\left(4 k+4 k \lambda-4 \beta \lambda k-\lambda \theta^{2}-\theta^{2}\right) \quad /[4 k$ $\left.\left(\lambda \beta^{2}+\lambda+1\right)-(\lambda+1) \theta^{2}\right]\left[4 k-\theta^{2}+\lambda\left(8 k-\theta^{2}\right)\right] \quad\left(4 k-\theta^{2}\right)$ $>0$, and $\partial\left(\bar{\pi}_{m A}^{*}-\pi_{m A}^{*}\right) / \partial \lambda=2 \beta k^{2}(a-c)^{2}(1-\beta)\left(16 B k^{2}+\right.$ $\left.8 \theta^{2}(1+\lambda) 1(+\lambda-\beta \lambda) k-\theta^{4}(1+\lambda)^{2}\right) /\left[4 k\left(\lambda \beta^{2}+\lambda+1\right)-(\lambda+\right.$ 1) $\left.\theta^{2}\right]^{2}\left[4 k-\theta^{2}+\lambda\left(8 k-\theta^{2}\right)\right]^{2}>0$, where $B=1+2 \lambda+$ $\lambda^{2}-2 \beta \lambda-3 \beta \lambda^{2}-\beta^{2} \lambda^{2}-\beta^{3} \lambda^{2}$. Because $0<\beta<1,0<\lambda<1$, $a>c$, and $k$ is large.

Sufficiently, it is clear that $\bar{\pi}_{m A}^{*}-\pi_{m A}^{*}>0$ and $\operatorname{sign}\left[\partial\left(\bar{\pi}_{m A}^{*}-\pi_{m A}^{*}\right) / \partial \lambda\right]=\operatorname{sign}(B)$. Therefore, $\partial\left(\bar{\pi}_{m A}^{*}-\pi_{m A}^{*}\right)$ $/ \partial \lambda>0$ unless $B<0$, which is graphically illustrated as Domain $\mathrm{E}$ in Figure 1.

Secondly, from $\pi_{r s}^{*}=k^{2}(a-c)^{2} /\left(4 k-\theta^{2}\right)^{2}, \pi_{r f}^{*}=k^{2}(a$ $-c)^{2}(4 \lambda+1)(2 \lambda+1) /\left(4 k-\theta^{2}+\lambda\left(8 k-\theta^{2}\right)\right)^{2} \bar{\pi}_{r s}^{*}=k^{2}(a$ $-c)^{2} \quad\left(2 \lambda \beta^{2}+\lambda+1\right)^{2} \quad /\left[4 k\left(\lambda \beta^{2}+\lambda+1\right)-(\lambda+1) \theta^{2}\right]^{2}$, and $\bar{\pi}_{r f}^{*}=k^{2}(a-c)^{2}\left(2 \lambda \beta^{2}+\lambda \beta+\lambda+1\right)\left(2 \lambda \beta^{2}-\lambda \beta+\lambda+1\right) /$ $\left[4 k\left(\lambda \beta^{2}+\lambda+1\right)-(\lambda+1) \theta^{2}\right]^{2}$, there are $\bar{\pi}_{r A}^{*}-\pi_{r A}^{*}=\left(\beta \bar{\pi}_{r f}^{*}\right.$ $\left.+(1-\beta) \bar{\pi}_{r s}^{*}\right)-\left(\beta \pi_{r f}^{*}+(1-\beta) \pi_{r s}^{*}\right)=\lambda \beta k^{2}(a-c)^{2}(1-\beta) J /$ $\left[4 k\left(\lambda \beta^{2}+\lambda+1\right)-(\lambda+1) \theta^{2}\right]^{2}\left[4 k-\theta^{2}+\lambda\left(8 k-\theta^{2}\right)\right]^{2}(4 k$ $\left.-\theta^{2}\right)^{2}<0$, where $J=256(2 \lambda+1)\left(2 \beta^{3} \lambda^{2}-4 \beta^{2} \lambda^{2}-3 \beta^{2} \lambda\right.$ $\left.+2 \beta \lambda^{2}+2 \beta \lambda-2 \lambda^{2}-4 \lambda-2\right) k^{4}+\cdots<0$, and $\partial\left(\pi_{r A}^{*}-\bar{\pi}_{r A}^{*}\right) / \partial \lambda$ $=-2 \beta k^{2}(a-c)^{2}(1-\beta) K /\left[4 k\left(\lambda \beta^{2}+\lambda+1\right)-(\lambda+1) \theta^{2}\right]^{3}$

$\left[4 k-\theta^{2}+\lambda\left(8 k-\theta^{2}\right)\right]^{3}>0, \quad$ where $K=256(2 \lambda+1)\left(\beta^{5} \lambda^{3}\right.$ $+\beta^{4} \lambda^{3}+4 \beta^{3} \lambda^{3}+3 \beta^{3} \lambda^{2}-4 \beta^{2} \lambda^{3}-5 \beta^{2} \lambda^{2}+2 \beta \lambda^{3}-2 \beta^{2} \lambda+5 \beta \lambda^{2}$ $\left.-\lambda^{3}+2 \beta \lambda-3 \lambda^{2}-3 \lambda-1\right) k^{4}+\cdots<0 \quad$ because $0<\beta<1$, $0<\lambda<1, a>c$, and $k$ is sufficiently large.

Thirdly, by calculating, $\bar{\pi}_{t A}^{*}-\pi_{t A}^{*}=\left(\bar{\pi}_{m A}^{*}+\bar{\pi}_{r A}^{*}\right)-\left(\pi_{m A}^{*}\right.$ $\left.+\pi_{r A}^{*}\right)=-\lambda \beta k^{2}(1-\beta)(a-c)^{2} L / 4\left[k\left(\lambda \beta^{2}+\lambda+1\right)-(\lambda+1)\right.$ $\left.\theta^{2}\right]^{2}\left[4 k-\theta^{2}+\lambda\left(8 k-\theta^{2}\right)\right]^{2}\left(4 k-\theta^{2}\right)^{2}<0$, where $L=256$ $\lambda \beta^{2}(2 \lambda+1)^{2} k^{4}+\cdots>0$, and $\partial\left(\pi_{t A}^{*}-\bar{\pi}_{t A}^{*}\right) / \partial \lambda=-2 \beta k^{2}(1-$ $\beta)(a-c)^{2} M /\left[4 k\left(\lambda \beta^{2}+\lambda+1\right)-(\lambda+1) \theta^{2}\right]^{3}\left[4 k-\theta^{2}+\lambda(8 k\right.$ $\left.\left.-\theta^{2}\right)\right]^{3}<0$, where $M=256 \lambda \beta^{2}(2 \lambda+1)^{3} k^{4}+\cdots>0$ because $0<\beta<1,0<\lambda<1, a>c$, and $k$ is sufficiently large. Q. E. $D$.

\section{Data Availability}

No data used to support this study.

\section{Conflicts of Interest}

The authors declare that they have no conflicts of interest.

\section{Acknowledgments}

This research was supported by the National Natural Science Foundation of China under Grant 71802031.

\section{References}

[1] S.-M. Hosseini-Motlagh, S. Ebrahimi, and A. Jokar, "Sustainable supply chain coordination under competition and green effort scheme," Journal of the Operational Research Society, vol. 72, no. 2, pp. 304-319, 2021.

[2] S. M. Hosseini-Motlagh, S. Ebrahimi, N. Nami, and J. Ignatius, "Supply chain coordination through lead time crashing in a socially responsible supply chain considering transportation modes and carbon emissions tax," International Journal of Transportation Engineering, vol. 6, no. 4, pp. 331-354, 2019.
[3] Q. P. Wang and L. F. He, "Incentive strategies for low-carbon supply chains with asymmetric information of carbon reduction efficiency," International Journal of Environmental Research and Public Health, vol. 15, no. 12, p. 2736, 2018.

[4] L. Yang, J. N. Ji, and C. S. Zheng, "Impact of asymmetric carbon information on supply chain decisions under lowcarbon policies," Discrete Dynamics in Nature and Society, vol. 2016, Article ID 1369589, 2016.

[5] X. Yun, H. Liu, Y. Li, K. K. Lai, and Lai, "Contract design under asymmetric demand information for sustainable supply chain practices," Annals of Operations Research, 2021.

[6] A. Raj, N. M. Modak, P. Kelle, and B. Singh, "Analysis of a dyadic sustainable supply chain under asymmetric information," European Journal of Operational Research, vol. 289, no. 2, pp. 582-594, 2021.

[7] J. Li and K. K. Lai, "The abatement contract for low-carbon demand in supply chain with single and multiple abatement mechanism under asymmetric information," Annals of $\mathrm{Op}$ erations Research, 2021.

[8] Q. Han, Y. Y. Wang, L. Shen, and W. Q. Dong, "Decision and coordination of low-carbon e-commerce supply chain with government carbon subsidies and fairness concerns," Complexity, vol. 2020, Article ID 1974942, 2020.

[9] J. Jian, B. Li, N. Zhang, and J. F. Su, "Decision-making and coordination of green closed-loop supply chain with fairness concern," Journal of Cleaner Production, vol. 298, Article ID 126779, 2021.

[10] H. Zou, J. Qin, and B. Dai, “Optimal pricing decisions for a low-carbon supply chain considering fairness concern under carbon quota policy," International Journal of Environmental Research and Public Health, vol. 18, no. 2, p. 556, 2021.

[11] E. Katok and V. Pavlov, "Fairness in supply chain contracts: a laboratory study," Journal of Operations Management, vol. 31, no. 3, pp. 129-137, 2014.

[12] S. Choi and P. R. Messinger, "The role of fairness in competitive supply chain relationships: an experimental study," European Journal of Operational Research, vol. 251, no. 3, pp. 798-813, 2016.

[13] J. Zhou, R. Zhao, and W. Wang, "Pricing decision of a manufacturer in a dual-channel supply chain with asymmetric information," European Journal of Operational Research, vol. 278, no. 3, pp. 809-820, 2019.

[14] T. Chernonog and T. Avinadav, "Pricing and advertising in a supply chain of perishable products under asymmetric information," International Journal of Production Economics, vol. 209, no. S1, pp. 249-264, 2019.

[15] P. Zhang and Z. K. Xiong, "Information sharing in a closedloop supply chain with asymmetric demand forecasts," Mathematical Problems in Engineering, vol. 2017, Article ID 9785759, 2017.

[16] X. H. Gan, S. P. Sethi, and J. Zhou, "Commitment-penalty contracts in drop-shipping supply chains with asymmetric demand information," European Journal of Operational Research, vol. 204, no. 3, pp. 449-462, 2011.

[17] Y. Li, X. Xu, X. Zhao, J. H. Yeung, Y. Van, and F. Ye, "Supply chain coordination with controllable lead time and asymmetric information," European Journal of Operational Research, vol. 217, no. 1, pp. 108-119, 2012.

[18] K. B. Chen, R. X. Xu, and H. W. Fang, "Information disclosure model under supply chain competition with asymmetric demand disruption," Asia Pacific Journal of Operational Research, vol. 33, no. 6, Article ID 1650043, 2016.

[19] S. Zhang and J. Zhang, "Contract preference with stochastic cost learning in a two-period supply chain under asymmetric 
information," International Journal of Production Economics, vol. 196, no. 1, pp. 226-247, 2018.

[20] R. N. Yang and L. J. Ma, "Two-part tariff contracting with competing unreliable suppliers in a supply chain under asymmetric information," Annals of Operations Research, vol. 257, no. 1, pp. 559-585, 2017.

[21] X. Ma, S. Wang, S. M. N. Islam, and X. Liu, "Coordinating a three-echelon fresh agricultural products supply chain considering freshness-keeping effort with asymmetric information," Applied Mathematical Modelling, vol. 67, no. 3, pp. 337-356, 2019.

[22] M. Li, X. Zhang, and B. Dan, "Competition and cooperation in a supply chain with an offline showroom under asymmetric information," International Journal of Production Research, vol. 58, no. 19, pp. 5964-5979, 2020.

[23] K. Zhu, J. Shen, and X. Yao, "A three-echelon supply chain with asymmetric information under uncertainty," Journal of Ambient Intelligence and Humanized Computing, vol. 10, no. 2, pp. 579-591, 2019.

[24] F. Qin, F. Mai, M. J. Fry, and A. S. Raturi, "Supply-chain performance anomalies: fairness concerns under private cost information," European Journal of Operational Research, vol. 252, no. 1, pp. 170-182, 2016.

[25] Z. H. Cao, Y. Y. Wang, J. Zhao, and J. Min, "Store brand introduction and quantity decision under asymmetric cost information in a retailer-led supply chain," Computers \& Industrial Engineering, vol. 152, Article ID 106995, 2021.

[26] E. B. Cao, Y. J. Ma, C. Wan, and M. Y. Lai, "Contracting with asymmetric cost information in a dual-channel supply chain," Operations Research Letters, vol. 41, no. 4, pp. 410-414, 2014.

[27] Q. H. Zhang and J. W. Luo, "Coordination of a buyer-vendor supply chain for a perishable product under symmetric and asymmetric information," Asia Pacific Journal of Operational Research, vol. 28, no. 5, pp. 673-688, 2011.

[28] J. Zhang, W. Tang, L. Feng, and M. Hu, "A principal-agent model in a supplier-led supply chain under asymmetric information," IMA Journal of Management Mathematics, vol. 25, no. 2, pp. 185-201, 2014.

[29] D. Yang, T. Xiao, T.-M. Choi, and T. C. E. Cheng, "Optimal reservation pricing strategy for a fashion supply chain with forecast update and asymmetric cost information," International Journal of Production Research, vol. 56, no. 5, pp. 1960-1981, 2018.

[30] D. Wang, Z. Wang, B. Zhang, and L. Zhu, "Vendor-managed inventory supply chain coordination based on commitmentpenalty contracts with bilateral asymmetric information," Enterprise Information Systems, pp. 1-18, 2020.

[31] S. L. Gu, H. M. Guo, and Y. S. Su, "Research on supply chain coordination and profit allocation based on altruistic principal under bilateral asymmetric information," Discrete Dynamics in Nature and Society, vol. 2018, Article ID 2302434, 2018.

[32] Z. Mobini, W. van den Heuvel, and A. Wagelmans, "Designing multi-period supply contracts in a two-echelon supply chain with asymmetric information," European Journal of Operational Research, vol. 277, no. 2, pp. 542-560, 2019.

[33] T.-H. Ho, X. Su, and Y. Wu, "Distributional and peer-induced fairness in supply chain contract design," Production and Operations Management, vol. 23, no. 2, pp. 161-175, 2014.

[34] N. Wang, Z. P. Fan, and X. Chen, "Effect of fairness on channel choice of the mobile phone supply chain," International Transactions in Operational Research, vol. 28, no. 4, pp. 2110-2138, 2021.
[35] Y. Y. Wang, Z. Q. Yu, L. Shen, Y. Ge, and J. Li, "Different dominant models and fairness concern of e-supply chain," "Complexity, vol. 2018, Article ID 8616595, 2018.

[36] Y. Y. Wang, R. J. Fan, L. Shen, and M. Z. Jin, "Decisions and coordination of green e-commerce supply chain considering green manufacturer's fairness concerns," International Journal of Production Research, vol. 58, no. S1, pp. 7471-7489, 2020.

[37] B. Yan, J. Wu, Z. Jin, and S. He, "Decision-making of fresh agricultural product supply chain considering the manufacturer's fairness concerns," 4Or, vol. 18, no. 1, pp. 91-122, 2020.

[38] B. Li, P. W. Hou, and Q. H. Li, "Cooperative advertising in a dual-channel supply chain with a fairness concern of the manufacturer," IMA Journal of Management Mathematics, vol. 28, no. 2, pp. 259-277, 2017.

[39] Y. Zhou, M. Bao, X. Chen, and X. Xu, "Co-op advertising and emission reduction cost sharing contracts and coordination in low-carbon supply chain based on fairness concerns," Journal of Cleaner Production, vol. 133, no. 10, pp. 402-413, 2016.

[40] S. Sarkar and S. Bhala, "Coordinating a closed loop supply chain with fairness concern by a constant wholesale price contract," European Journal of Operational Research, vol. 295, no. 1, pp. 1-11, 2021.

[41] X. J. Du and W. J. Zhao, "Managing a dual-channel supply chain with fairness and channel preference," Mathematical Problems in Engineering, vol. 2021, Article ID 6614692, 2021.

[42] Z. Liu, X. X. Zheng, D. F. Li, C. N. Liao, and J. B. Shehu, "A novel cooperative game-based method to coordinate a sustainable supply chain under psychological uncertainty in fairness concerns," Transportation Research Part E: Logistics and Transportation Review, vol. 147, Article ID 102237, 2021.

[43] T. Nie and S. Du, "Dual-fairness supply chain with quantity discount contracts," European Journal of Operational Research, vol. 258, no. 2, pp. 491-500, 2017.

[44] F. Zhang, Z. Hu, Y. Z. Yang, and X. G. Ma, "Complex dynamics analysis of closed-loop supply chain considering CSR and fairness concerns," Discrete Dynamics in Nature and Society, vol. 2021, Article ID 7787420, 2021.

[45] X. Li, X. Cui, Y. Li, D. Xu, and F. Xu, "Optimisation of reverse supply chain with used-product collection effort under collector's fairness concerns," International Journal of Production Research, vol. 59, no. 2, pp. 652-663, 2021.

[46] W. H. Liu, S. Q. Wang, L. D, Zhu, D. Wang, and X. R. Shen, "Order allocation of logistics service supply chain with fairness concern and demand updating: model analysis and empirical examination," Annals of Operations Research, vol. 268, no. S1, pp. 177-213, 2018.

[47] J. Tao, L. Shao, Z. Guan, W. Ho, and S. Talluri, "Incorporating risk aversion and fairness considerations into procurement and distribution decisions in a supply chain," International Journal of Production Research, vol. 58, no. 7, pp. 1950-1967, 2019.

[48] Q. X. Li, M. N. Shi, and Y. M. Huang, “A Dynamic price game model in a low-carbon, closed-loop supply chain considering return rates and fairness concern behaviors," International Journal of Environmental Research and Public Health, vol. 16, no. 11, p. 1978, 2019.

[49] H. X. Yang, E. L. Shao, Y. Y. Gong, and X. L. Guan, "Decisionmaking for green supply chain considering fairness concern based on trade credit," IEEE Access, vol. 9, Article ID 67684, 2021.

[50] A. Adhikari and A. Bisi, "Collaboration, bargaining, and fairness concern for a green apparel supply chain: an 
emerging economy perspective," Transportation Research Part E, vol. 135, no. 3, Article ID 101863, 2020.

[51] B. Yan, Y. R. Chen, and S. Y. He, "Decision making and coordination of fresh agriculture product supply chain considering fairness concerns," RAIRO - operations Research, vol. 54, no. 4, pp. 1231-1248, 2020.

[52] X. P. Zhen, D. Shi, S. B. Tsai, and W. Wang, "Pricing decisions of a supply chain with multichannel retailer under fairness concerns," Mathematical Problems in Engineering, vol. 2019, Article ID 9547302, 2019.

[53] Y. M. Jiang, X. L. Wu, B. Chen, and Q. Y. Hu, "Rawlsian fairness in push and pull supply chains," European Journal of Operational Research, vol. 291, no. 1, pp. 194-205, 2021.

[54] K. W. Pan, Z. B. Cui, A. X. Xing, and Q. H. Lu, "Impact of fairness concern on retailer-dominated supply chain," Computers \& Industrial Engineering, vol. 139, no. 1, Article ID 106209, 2020.

[55] W. Jiang, L. Yuan, L. J. Wu, and S. Y. Guo, "Carbon emission reduction and profit distribution mechanism of construction supply chain with fairness concern and cap-and-trade," PLoS One, vol. 14, no. 10, p. e022415, 2019.

[56] N. Du and Q. L. Han, "Pricing and service quality guarantee decisions in logistics service supply chain with fairness concern," Asia Pacific Journal of Operational Research, vol. 35, no. 5, Article ID 1850036, 2018.

[57] J. C. Li, J. H. Lu, Q. L. Wang, and C. W. Li, "Quality and pricing decisions in a two-echelon supply chain with Nash bargaining fairness concerns," Discrete Dynamics in Nature and Society, vol. 2018, Article ID 4267305, 2018.

[58] Z. J. Zhang, P. Wang, M. Y. Wan, J. H. Guo, and C. L. Luo, "Interactive impacts of overconfidence and fairness concern on supply chain performance," Advances in Production Engineering \& Management, vol. 15, no. 3, pp. 277-294, 2020.

[59] Y. M. Huang, Q. X. Li, and Y. H. Zhang, "The complexity analysis for price game model of risk-averse supply chain considering fairness concern," Complexity, vol. 2018, Article ID 9216193, 2018.

[60] A. M. Spence, "Job market signaling," Quarterly Journal of Economics, vol. 87, no. 3, pp. 355-374, 1973.

[61] J. Ni, L. Zhao, and L. K. Chu, "Supply contracting and process innovation in a dynamic supply chain with information asymmetry," European Journal of Operational Research, vol. 288, no. 2, pp. 552-462, 2020.

[62] D. Ghosh and J. Shah, "A comparative analysis of greening policies across supply chain structures," International Journal of Production Economics, vol. 135, no. 2, pp. 568-583, 2012.

[63] M. Sinayi and M. Rasti-Barzoki, "A game theoretic approach for pricing, greening, and social welfare policies in a supply chain with government intervention," Journal of Cleaner Production, vol. 196, no. 9, pp. 1443-1458, 2018.

[64] S. Swami and J. Shah, "Channel coordination in green supply chain management," Journal Of The Operational Research Society, vol. 64, no. 3, pp. 336-351, 2013.

[65] E. Fehr and K. M. Schmidt, "A theory of fairness, competition and cooperation," Quarterly Journal of Economics, vol. 114, no. 3, pp. 817-868, 1999.

[66] J. B. Li, X. S. Fan, and B. Dai, "Fairness of extra-gain guilty in performance of supply chain and contract design," Journal of Systems Science and Complexity, vol. 30, no. 4, pp. 866-882, 2017.

[67] S. F. Du, T. F. Nie, C. B. Chu, and Y. G. Yu, "Newsvendor model for a dyadic supply chain with Nash bargaining fairness concerns," International Journal of Production Research, vol. 52, no. 17, pp. 5070-5085, 2014.
[68] L. Zhang, B. Xue, and X. Liu, "Carbon emission reduction with regard to retailer's fairness concern and subsidies," Sustainability, vol. 10, no. 4, p. 1209, 2018.

[69] G. X. Wei, B. Bary, and Y. H. Qin, "Sorted or pooled? Optimal tournament design for heterogeneous contestants," Journal of Networks Software Tools and Applications, vol. 22, no. 5, pp. 12641-12648, 2019. 